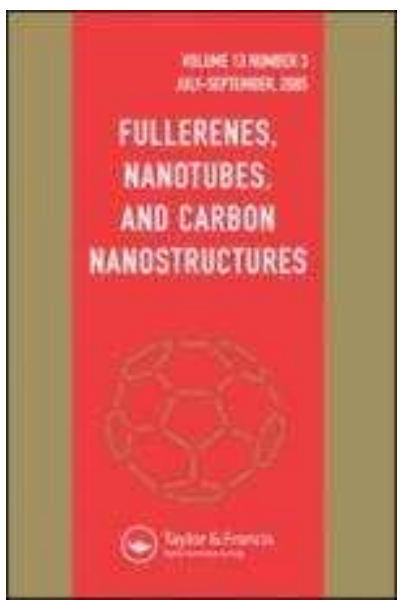

\title{
Layer-by-Layer Polypyrrole Coated Graphite Oxide and Graphene Nanosheets as Catalyst Support Materials for Fuel Cells
}

\begin{tabular}{|c|c|}
\hline Journal: & Fullerenes, Nanotubes and Carbon Nanostructures \\
\hline Manuscript ID: & Draft \\
\hline Manuscript Type: & Original Article \\
\hline $\begin{array}{r}\text { Date Submitted by the } \\
\text { Author: }\end{array}$ & $\mathrm{n} / \mathrm{a}$ \\
\hline Complete List of Authors: & $\begin{array}{l}\text { Saner, Burcu; Sabanci University, Faculty of Engineering and } \\
\text { Natural Sciences } \\
\text { Alkan Gürsel, Selmiye; Sabanci University, Faculty of Engineering } \\
\text { and Natural Sciences } \\
\text { Yürüm, Yuda; Sabanci University }\end{array}$ \\
\hline Keywords: & $\begin{array}{l}\text { graphite oxide, graphene nanosheets, conducting polymer, } \\
\text { nanocomposites, catalyst support }\end{array}$ \\
\hline
\end{tabular}

\section{SCHOLARONE ${ }^{\text {M }}$ Manuscripts}




\title{
Layer-by-Layer Polypyrrole Coated Graphite Oxide and Graphene Nanosheets as Catalyst Support Materials for Fuel Cells
}

\author{
BURCU SANER, SELMIYE ALKAN GÜRSEL, YUDA YÜRÜM*
}

Faculty of Engineering and Natural Sciences, Sabanci University,

Tuzla, Istanbul 34956, Turkey

* Author to whom correspondence should be addressed

(yyurum@sabanciuniv.edu, Tel: +90 2164839512 Fax: +90 2164839550 ) 
For the production of advanced type of catalyst support materials, the distinguished properties of graphene nanosheets were combined with the structural properties of conducting polypyrrole by the incorporation of graphene nanosheets into a polymer matrix by the proposed simple and low-cost fabrication technique. A precise tuning of electrical conductivity and thermal stability was also achieved by controlling the thickness of randomly dispersed graphene nanosheets by a layer-by-layer polymer coating. Initially, graphene nanosheets were fabricated in large quantities via a mild chemical synthetic route involving graphite oxidation, ultrasonic treatment and chemical reduction. Then, polypyrrole/graphene nanosheet composites with improved conductivity, thermal stability and high surface area were synthesized by in situ polymerization with the different pyrrole feed ratios. Although graphite oxide sheets have electrically insulating property, partially oxidized graphite oxide was also utilized as conductive fillers in polymer matrix. However, polypyrrole/graphene nanosheet composites have better electrical conductivity than polypyrrole/graphite oxide composites.

Keywords Graphite oxide, graphene nanosheets, conducting polymer, nanocomposites, catalyst support 


\section{Introduction}

Fuel cells are clean, compact and modular energy generation devices that generate electricity by a chemical reaction between a fuel and an oxidant. Polymer electrolyte membrane fuel cell (PEMFC) offers several advantages for both mobile and stationary applications yet it is necessary to develop low cost and more efficient PEMFCs. The heart of the PEMFC is the membrane electrode assembly composed of a proton exchange membrane sandwiched between two porous gas diffusion electrodes. These electrodes are made up of a catalyst support material or gas diffusion layer and a catalyst layer. Catalyst support materials have significant effect on the cost, performance and the durability of PEMFCs. The ideal support materials should provide high dispersion, utilization, activity, and stability for the catalyst especially platinum (Pt) (1-3). Carbon black has been extensively used as a catalyst support for Pt in PEMFC. However, alternatives to carbon black are still needed to enhance catalyst utilization and reduce the cost.

Novel nanostructured carbon materials (carbon nanofibers, carbon nanotubes and graphene) have generated intense interest as catalyst supports in PEMFCs due to their unique structures and properties $(4,5)$. However, the main drawbacks of these materials are high production cost and mass production. At this point, graphene nanosheets can serve as the promising catalyst support because of its low-cost and large-scale production. In addition, free standing graphene sheets have large surface area, high thermal and electrical conductivity, and high mobility of charge carriers (6). According to Saner et al. (7) a few graphene layers provide effective surface area to improve metal-support interaction. Authors proposed a mild chemical exfoliation method for the reduction of layer number in graphitic structure and the production in large quantities of 
graphene nanosheets in order to utilize multiple graphene nanosheets as the catalyst support materials in fuel cells. Rao et al. (8) demonstrated that graphene could be a good candidate as an electrode in supercapacitors because the specific capacitance of the exfoliated graphene in the aqueous electrolyte was better than activated carbons and carbon nanotubes. In another work, Ruoff et al. (9) showed that chemically modified graphene was incorporated into ultracapacitor test electrodes in order to increase the energy density of the packaged ultracapacitor by increasing the electrode thickness and eliminating additives.

Conducting polymers have high conductivity, are lightweight, inexpensive, flexible, airstable, and environmentally friendly but the major obstacle of conducting polymers as an electrode material is the degradation during cycling because of the volume change of the polymer due to the insertion/deinsertion of counter ions (10). Therefore, nanocomposites based on conducting polymers and carbon nanomaterials can be used as a potential catalyst support to improve the properties of supports and extend life cycle of fuel cells. There have been several attempts for the synthesis of these type of nanocomposites. Previously, Wang et al. (11) reported that the remarkable electrical conductivity and specific capacitance of graphene/polyaniline composites as a supercapacitor electrode material. Recently, a study was published on a graphene/polyaniline composite paper by in situ anodic electropolymerization of aniline monomer as a polyaniline film on graphene paper (12).

In this paper, we present the preparation of new nanocomposites by combining the distinguished properties of graphene with the structural properties of a conducting polymer by incorporation of graphene into a polymer matrix. Moreover, we employed partially oxidized graphite oxide (GO) sheets instead of fully oxidized GO sheets as conductive fillers in polymer matrix to enhance the electrical conductivity. Among the 
various conducting materials, polypyrrole (PPy) has taken special attention because of its relatively easy processability, electrical conductivity, and environmental stability (13). Graphene nanosheets are electron acceptors while the conducting polymer serves as an electron donor (14). In this study, graphene nanosheets were fabricated in large quantities by adopting a safer and mild chemical route including oxidation, ultrasonic treatment and chemical reduction (7). PPy was coated on GO sheets and graphene nanosheets by in situ polymerization with different pyrrole (Py) feed ratios. The influence of the feeding ratios on the morphologies, crystal structures, thermal properties, and electrical conductivities of PPy/GO and PPy/graphene nanosheet based nanocomposites were investigated systematically by various characterization techniques. 


\title{
Experimental
}

\author{
Materials \\ Graphite flake (Sigma Aldrich); acetic anhydride (Merck, extra pure); sulfuric acid \\ (Fluka, 95-97\%); potassium dichromate, (Chempur, 99.9\%); hydroquinone (Acros, \\ 99\%); sodium hydroxide (Merck, 97\%), pyrrole (Merck, 98\%), $\mathrm{FeCl}_{3}$ (Aldrich, 97\%).
}

\section{Separation of graphene nanosheets}

Graphene nanosheets were produced by a safer and mild chemical route consists of oxidation, ultrasonic treatment and chemical reduction in large quantities (7). At first, potassium dichromate $(10.5 \mathrm{~g})$, sulfuric acid $(150 \mathrm{~mL})$ and $7.5 \mathrm{~mL}$ distilled water were mixed in ice-bath to prepare chromic acid as an oxidizing agent. Then, graphite flakes (5 g) were added into chromic acid and stirred for a while at room temperature to provide homogenous distribution of flakes in the acid. At last, acetic anhydride $(5 \mathrm{~g})$ as an intercalating agent was added dropwise into the mixture and the mixture was stirred at $45{ }^{\circ} \mathrm{C}$ for 10 days. Graphite oxide (GO) was obtained by filtration and neutralization with $0.1 \mathrm{M} \mathrm{NaOH}$ and distilled water. Ultrasonic treatment was performed for the homogenous dispersion of GO sheets in water around $1 \mathrm{~h}$ at room temperature. Sonicated GO sheets were reduced through refluxing in hydroquinone and distilled water under $\mathrm{N}_{2}$ atmosphere for 24 hours. Then, the products were washed with distilled water. At the end of each step, samples were dried in a vacuum oven at $60{ }^{\circ} \mathrm{C}$ overnight. 


\section{Synthesis of polypyrrole/graphene nanosheet-based nanocomposites}

Pristine polypyrrole (PPy) was synthesized by using Py (0.0447 mol) as the monomer and $\mathrm{FeCl}_{3}(0.107 \mathrm{~mol})$ as the oxidant in the mixture of $\mathrm{H}_{2} \mathrm{O}$ and ethanol in $1: 1(\mathrm{v} / \mathrm{v})$ under $\mathrm{N}_{2}$ atmosphere (13). The $\mathrm{Fe}^{3+} / \mathrm{Py}$ molar ratio was adjusted as 2.4 (15). At the beginning, the reaction mixture was placed in an ice bath about $1 \mathrm{~h}$ to prevent a sudden heating. Then, the mixture was stirred at room temperature for $24 \mathrm{~h}$.

PPy was coated on both GO sheets and graphene nanosheets by in situ polymerization of $\mathrm{Py}$ at room temperature under $\mathrm{N}_{2}$ atmosphere for $24 \mathrm{~h}$. The precipitated sample was filtered and rinsed several times by ethanol and distilled water to remove excess Py, catalyst and side products. The black powder was dried under vacuum at $60{ }^{\circ} \mathrm{C}$ for $24 \mathrm{~h}$. The feeding mass ratios of Py and nanosheets were 1:1 and 2:1.

Composites were converted into the pellet form under adjusted pressure by using PPy/graphene nanosheet nanocomposites to measure their electrical conductivities.

\section{Characterization}

The morphologies of nanocomposites were examined by a Leo Supra 35VP Field Emission Scanning Electron Microscope (SEM).

Powder X-ray diffraction (XRD) measurements of samples were performed with a Bruker AXS Advance Powder Diffractometer fitted with a Siemens X-ray gun, using $\mathrm{Cu} \mathrm{K} \alpha$ radiation $\left(\lambda=1.5406 \AA\right.$ ). The samples were swept from $2 \square=10^{\circ}$ through to $90^{\circ}$ using default parameters of the program of the diffractometer that was equipped with Bruker AXS Diffrac PLUS software. The X-ray generator was set to $40 \mathrm{kV}$ at $40 \mathrm{~mA}$. 
Structural changes of samples were analyzed by Renishaw InVia Reflex Raman Microscopy System (Renishaw Plc., New Mills, Wotton-under-Edge Gloucestershire, UK) using a $514 \mathrm{~nm}$ argon ion laser in the range of 100 to $3200 \mathrm{~cm}^{-1}$.

Thermal behaviors of the samples were investigated by NETZSCH Thermal Gravimetric Analyzer (TGA). The heating rate was $10 \mathrm{~K} / \mathrm{min}$ to a final temperature of $700{ }^{\circ} \mathrm{C}$ under air atmosphere.

The surface areas of samples were measured by Quantachrome NOVA 2200e series Surface Analyzer. The determination was based on the measurements of the adsorption isotherms of nitrogen at $77 \mathrm{~K}$. The specific surface areas were evaluated with the Brunauer-Emmett-Teller (BET) method in the P/P0 range of 0.05-0.35. All samples were outgassed for $24 \mathrm{~h}$ at $150^{\circ} \mathrm{C}$.

The electrical conductivities of nanocomposites in pellet forms were measured by a conventional four-probe method at room temperature.

The surface morphologies of nanocomposites were analyzed by Ambiant Atomic Force Microscope (AFM) LAMF02-007, NanoMagnetics Instruments.

\section{Results and Discussion}

\section{Scanning electron microscopy}

PPy synthesized by oxidation of the monomer with $\mathrm{FeCl}_{3}$ had a form of fine black powder. SEM image of pristine PPy contained irregular sphere-like particles of PPy, Figure 1. Oxidizing agents and monomer concentration have a considerable influence on the formation of the PPy morphology (the sphere-like, the ribbon-like, the wire-like) during polymerization (16). Also, pure PPy is brittle, insoluble and infusible, and hence not processable. 
Smooth and rigid GO layers were seen in Figure 2a. After PPy coating, laminated structure of GO sheets was observed clearly in SEM image, Figure 2b. Py monomer dispersed into the layers of GO and all layers were covered by PPy after oxidative polymerization. Also, acetic anhydride used as an intercalating agent during oxidation extended the layer distance in graphite (7) and thus provided good dispersion of Py monomer through GO layers during polymerization.

\section{-Figure 2-}

GO sheets were dispersed via ultrasonic treatment and then dispersed sheets were reduced by hydroquinone (7). Separated graphene nanosheets obtained by chemical reduction are presented in Figure 3a. Py intercalated into graphene nanosheets during in situ polymerization and polymerized on graphene nanosheets layer by layer. Uniformly layer coating of PPy/graphene nanosheet composites and spherical morphology of PPy nanoparticles on sheets were seen clearly in Figure 3b.

\section{-Figure 3-}

\section{$X$-ray diffraction analysis}

XRD pattern of pristine PPy was presented in Figure 4a. This result indicated that PPy had an amorphous structure. Graphite flakes were partially oxidized in the adjusted synthesis conditions using concentrated sulfuric acid, potassium dichromate, and acetic anhydride (7). XRD pattern of GO sheets showed low intensity of 002 diffraction peak at $2 \square=26.5^{\circ}$, Figure $4 \mathrm{~b}$. Longer oxidation time led to decrease in the intensity of 002 peak, enhanced the interlayer spacing between graphene sheets and switched the carbon backbone from $\mathrm{sp}^{2}$ to $\mathrm{sp}^{3}$ structure $(7,17)$. After covering of GO sheets by PPy with different feeding ratios, 002 peak intensity decreased and the peak was broadened. The intensity of 002 peak of Py:GO sheets=1:1 decreased down to $53 \mathrm{cps}$, Figure 4c. The 
intensity of 002 peak of Py:GO sheets=2:1 was down to $40 \mathrm{cps}$, Figure $4 \mathrm{~d}$. The structure of nanocomposites became more amorphous by increasing PPy content.

\section{-Figure 4-}

XRD data were also used to measure the percent crystallinities of GO sheets, PPy/GO nanocomposites, Figure 5. The area of (002) peak of $1 \mathrm{~g}$ pristine graphite was accepted as reference data and graphite flake was assumed as $100 \%$ crystalline. Also, PPy had an amorphous structure. After 10 days of oxidation, the percent crystallinity of GO sheets decreased down to nearly $1.8 \%$. After coating on GO surface by PPy (Py/GO sheet weight ratio: 1/1), the percent crystallinity of new materials decreased down to $\sim 0.6 \%$. Increasing the weight of $\mathrm{Py}$ in nanocomposites, the percent crystallinity became much lower. Accordingly, highly ordered substrates provide strong metal-support interaction and reduce self-poisoning (18). As the amount of GO sheets in nanocomposites increases, crystallinity increases, and this may enhance the deposition of Pt particles on well-ordered graphene oxide sheets.

\section{-Figure 5-}

\section{Raman spectroscopy}

In Raman spectrum, D band intensity changes with defects and disorder in sample, and $\mathrm{G}$ band intensity increases linearly by increasing flake thickness (19). The Raman spectrum of pristine PPy demonstrated the two bands at around $1380 \mathrm{~cm}^{-1}$ (D band) and $1561 \mathrm{~cm}^{-1}$ (G Band), Figure 6. In this spectrum, the characteristic D and G bands were due to the ring-stretching mode of PPy (20) and the $\mathrm{C}=\mathrm{C}$ backbone stretching of PPy (21), respectively.

\section{-Figure 6-}

During oxidation of graphite flakes, oxygen species diffused into the layers randomly and graphitic structure was distorted. There were three characteristic Raman 
bands of partially oxidized GO sheets which were the D band around $1354 \mathrm{~cm}^{-1}$, the $\mathrm{G}$ band around $1580 \mathrm{~cm}^{-1}$ and the 2D band around $2708 \mathrm{~cm}^{-1}$, Figure 7.

\section{-Figure 7-}

The structural change could be observed by the intensity ratio of the D and $G$ bands, $\mathrm{I}_{\mathrm{D}} / \mathrm{I}_{\mathrm{G}}$. This ratio directly correlated with the size of the crystalline grains or interdefect distance and this was also used to estimate the amount of defects (22). In Raman spectra of PPy/GO sheet nanocomposites, Figure $8 \mathrm{a}$ and $8 \mathrm{~b}, \mathrm{I}_{\mathrm{D}} / \mathrm{I}_{\mathrm{G}}$ ratio decreased with the increase of the feeding mass ratio of Py to GO sheets. $\mathrm{I}_{\mathrm{D}} / \mathrm{I}_{\mathrm{G}}$ ratios of Py:GO sheets $=1: 1$ and Py:GO sheets $=2: 1$ were calculated as 0.66 and 0.63 , respectively. Therefore, the graphitic in-plane crystallite size, $\mathrm{L}_{\mathrm{a}}$, increased with the enhanced covering onto the surface of GO layers by PPy.

\section{-Figure 8-}

In the Raman spectrum of graphene nanosheets, the D band around $1364 \mathrm{~cm}^{-1}$, the G band around $1582 \mathrm{~cm}^{-1}$ and the $2 \mathrm{D}$ band around $2709 \mathrm{~cm}^{-1}$ appeared, Figure $9 \mathrm{a} . \mathrm{I}_{\mathrm{D}} / \mathrm{I}_{\mathrm{G}}$ ratios of GO sheets and graphene nanosheets were calculated as 0.25 and 0.31 , respectively. This increase in $\mathrm{I}_{\mathrm{D}} / \mathrm{I}_{\mathrm{G}}$ ratio indicated the stacking height of graphene sheets decreased by ultrasonic vibration and chemical reduction of GO sheets. After coating of PPy on graphene nanosheets, D and G bands broadened and their intensities increased, Figure 9b. G band intensity is directly proportional to the graphitic in-plane crystallite size, $L_{a}(23)$. Therefore, increasing $G$ band intensity revealed that polymer thickness increased after covering of graphene nanosheets by PPy.

\section{-Figure 9-}


In addition, the thickness of graphite flake, GO sheets and reduced GO sheets were compared regarding to the change of $\mathrm{I}_{\mathrm{D}} / \mathrm{I}_{\mathrm{G}}$ ratio. In Figure 10 showed $\mathrm{I}_{\mathrm{D}} / \mathrm{I}_{\mathrm{G}}$ ratio change of graphite flake, partially oxidized GO sheets and reduced GO sheets. After each chemical reaction, $I_{D} / I_{G}$ ratio increased, and thus flake thickness decreased (19). This indicated that how stepwise chemical procedure influenced the morphology of graphite.

\section{-Figure 10-}

\section{Thermogravimetric analysis}

Figure 11 indicated the thermogravimetric curves of GO sheets, pristine PPy, PPy/GO nanocomposites synthesized with different feeding mass ratios. The weight loss curve of nanocomposites appeared between pristine PPy and GO sheets. When comparing to thermal behavior of PPy, PPy/GO sheet nanocomposites had an improved thermal stability. In addition, thermal stability decreased by increasing PPy content in GO layers. The percent weight changes of materials as a function of increasing temperature were also analyzed by TGA. GO sheets started to lose weight at about $350{ }^{\circ} \mathrm{C}$ due to the thermal decomposition of acetic anhydride into $\mathrm{CO}_{2}$ and $\mathrm{H}_{2} \mathrm{O}$ vapor which swelled the layered graphitic structure. Pristine PPy was quite stable up to $150{ }^{\circ} \mathrm{C}$ and began to degrade at temperatures higher than $150{ }^{\circ} \mathrm{C}$. As the amount of PPy was increased in PPy/GO nanocomposites, the decomposition temperature decreased. The thermal stabilities of these composites were much higher than pristine PPy. The amount of weight losses of pristine PPy, GO sheets, Py:GO sheets=1:1 and Py:GO sheets=2:1 at 700 oC were about $88 \%, 25 \%, 51 \%$ and $53 \%$, respectively. These differences also supported the stability of synthesized PPy/GO nanocomposites between pristine PPy and GO sheets. 
In Figure 12, thermal stabilities of graphene nanosheets, pristine PPy and Py:graphene nanosheets $=1: 1$ composite were compared between $25-700{ }^{\circ} \mathrm{C}$ under air atmosphere. Graphene nanosheets exhibited 5\% weight loss at about $310{ }^{\circ} \mathrm{C}$. Graphene nanosheets effectively reinforced the PPy matrix in nanocomposite. Therefore, the mass loss of PPy/graphene nanosheet composite during the thermal decomposition was approximately $5 \%$ of the initial mass at $300{ }^{\circ} \mathrm{C}$. However, the mass loss of PPy was about $5 \%$ at $150{ }^{\circ} \mathrm{C}$ and then rapid mass loss took place between $150{ }^{\circ} \mathrm{C}$ and $700{ }^{\circ} \mathrm{C}$. Consequently, mass loss percentage of nanocomposite was significantly less than pristine PPy. The amount of weight losses of pristine PPy, graphene nanosheets and Py:graphene nanosheets $=1: 1$ at $700{ }^{\circ} \mathrm{C}$ were about $88 \%, 56 \%$, and $70 \%$, respectively.

\section{-Figure 12-}

\section{Atomic force microscopy}

All AFM experiments were performed in tapping mode using a silicon cantilever probe. As Py concentration increased, the composite surface became smoother. 3D surface topography of PPy composites displayed smooth morphology, Figure 13a. As the amount of GO sheet increased, the height difference of surface increased due to ripples in GO sheets, Figure 13b. In addition, the functional groups such as epoxide, carbonyl, quinone, ketone, and hydroxyl on the basal plane of GO triggered corrugation or local puckering of the carbon skeleton (24). However, increasing the amount of PPy in the nanocomposite caused to reduce the topography variations which were observed in $3 \mathrm{D}$ AFM image, Figure 13c. 


\section{Electrical conductivity and surface area measurements}

The electrical conductivity of samples in the pellet form was measured by the conventional four-probe method. The electrical conductivity results of samples (pristine PPy, GO sheets, Py:GO sheet=1:1, and Py:GO sheet=2:1) were given in Table 1 . Conductivity of pristine PPy was relatively poor due to weak compactness and randomly orientation of PPy nanostructures and weak bonding between the polymer particles through the boundaries (25). Although GO is electrically insulating material, partially oxidized GO sheets can be utilized as a conductive filler to enhance the conductivity of PPy. The conductivity of GO sheets synthesized by a mild and safer oxidation method (7) was measured as $0.69 \mathrm{~S} / \mathrm{cm}$. The conductivity values of nanocomposites were between the values of pristine PPy and GO sheets and the increasing PPy content decreased the conductivity of nanocomposites. According to recently published works, in the production of GO-based nanocomposites, oxidation degree of GO sheets, oxidizing agents, intercalating agents, monomer type and concentration, and reaction media considerably affects the conductivities of composites $(26,27)$.

\section{- Table 1-}

The conductivity of reduced GO sheets was measured as $3.96 \mathrm{~S} / \mathrm{cm}$. After PPy was coated onto the surface of reduced GO sheets, the conductivity of the composite improved due to the better compactness and structure of PPy in the composite than in pristine PPy (Table 2). Therefore, nanocomposites including graphene nanosheets showed better conductivity when comparing nanocomposites including the partially oxidized GO sheets. 
High specific surface area is one of the main requirements for the enhancement of the dispersion and narrow distribution of catalytic metals on catalyst support materials. Nitrogen adsorption isotherms showed that BET surface area of reduced GO sheets was $507 \mathrm{~m}^{2} / \mathrm{g}$. Ruoff et al. (28) demonstrated that BET surface area of reduced GO sheets was measured as $466 \mathrm{~m}^{2} / \mathrm{g}$ via nitrogen gas absorption. This BET value was similar to one calculated by using our reduced GO sheets. After coating on reduced GO sheets by PPy, BET surface area of this nanocomposite was measured as $270 \mathrm{~m}^{2} / \mathrm{g}$. In PPy/graphene nanosheet composites, graphene nanosheets provided higher surface area and better electronic conductivity while PPy facilitated the electron transfer through the conducting matrix. Because of large aspect ratio and surface area of reduced GO sheets, they serve as effective percolative conducting bridges that increase the conductivity of nanocomposites (29).

\section{Conclusions}

GO sheets after a mild oxidation of graphite flakes and graphene nanosheets after chemical reduction of GO sheets were obtained in the present work. Both GO sheets and graphene nanosheets were coated by conducting PPy by in situ polymerization of Py monomer. The characteristic properties of PPy-based nanocomposites were tailored by changing the feeding mass ratio of Py to sheets. The intercalating agent between the graphene layers provided good dispersion in PPy matrix. Therefore, conductivity of nanocomposites increased after polymerization when comparing to pristine PPy. Furthermore, the electrical conductivity of PPy/GO nanosheet based composites slightly decreased with the increase of the feeding mass ratio of Py to GO nanosheets due to percolative behaviour. A layer by layer polymer coating on individual graphene nanosheets and GO sheets was clearly observed in SEM images and an increase of polymer thickness in these sheets was also supported by Raman spectroscopy analyses. 
PPy/graphene nanosheets including both characteristic properties of PPy and graphene nanosheets could be produced in large quantities by the proposed simple and low-cost fabrication technique. Consequently, PPy/graphene nanosheet composites with improved conductivity, thermal stability and high surface area are more advantageous as a catalyst support when comparing with $\mathrm{PPy} / \mathrm{GO}$ composites in order to achieve higher efficiency of the electrocatalyst in fuel cells. We also think the characteristic properties of PPy/GO sheet composites as catalyst support might be tailored by using GO sheets at different oxidation levels and the amount of functional groups may affect the dispersion and size of metal catalysts on these nanocomposites.

\section{Acknowledgments}

The authors would like to acknowledge to Prof. Dr. Levent Toppare from Middle East Technical University, Turkey for his help in four-probe measurements and Assoc. Prof. Mustafa Culha from Yeditepe University, Turkey for his help to use their Raman Spectroscopy. 


\section{References}

1. Haile, S. M. (2003) Fuel cell materials and components. Acta Materialia, 51: 59816000

2. Litster, S., and McLean, G. (2004) PEM fuel cell electrodes. J. Power Sources, 130: $61-76$.

3. Gubler, L., Beck, N., Alkan-Gürsel, S., Hajbolouri, F., Kramer, D., Reiner, A., Steiger, B., Scherer, G. G., Wokaun, A., Rajesh, B., and Thampi, K.R. (2004) Materials for polymer electrolyte fuel cells. Chimia, 58: 826-836.

4. Shao, Y., Liu, J., Wang, Y., and Lin, Y. (2009) Novel catalyst support materials for PEM fuel cells: current status and future prospects. J. Mater. Chem., 19: 46-59.

5. Centi, G., and Perathoner, S. (2009) The role of nanostructure in improving the performance of electrodes for energy storage and conversion. Eur. J. Inorg. Chem., 26, 3851-3878.

6. Park, S., and Ruoff, R. S. (2009) Chemical methods for the production of graphenes. Nature Nanotechnology, 4: 217-224.

7. Saner, B., Okyay, F., and Yürüm, Y. (2010) Utilization of multiple graphene layers in fuel cells 1 . An improved technique for the exfoliation of graphene-based nanosheets from graphite. Fuel, 89: 1903-1910.

8. Vivekchand, S. R. C., Rout, C. S., Subrahmanyam, K. S., Govindaraj, A., and Rao, C. N. R. (2008) Graphene-based electrochemical supercapacitors. J. Chem. Sci., 120: 913.

9. Stoller, M. D., Park, S., Zhu, Y., An, J., and Ruoff, R. S. (2008) Graphene-based ultracapacitors. Nano Lett., 8: 3498-3502. 
10. Sharma, A. K., Kim, J. -H., and Lee, Y. -S. (2009) An Efficient Synthesis of polypyrrole/carbon fiber composite nano-thin films. Int. J. Electrochem. Sci., 4: 15601567.

11. Wang, H., Ha, Q., Yang, X., Lu, L., and Wang, X. (2009) Graphene oxide doped polyaniline for supercapacitors. Electrochem. Comm., 11: 1158-1161.

12. Wang, D. W., Li, F., Zhao, J., Ren, W., Chen, Z. G., Tan, J., Wu, Z. S., Gentle, I., Lu, G. Q., and Cheng, H. M. (2009) Fabrication of graphene/polyaniline composite paper via in situ anodic electropolymerization for high-performance flexible electrode. ACS Nano, 3: 1745-1752.

13. Vernitskaya, T. V., and Efimov, O. N. (1997) Polypyrrole: a conducting polymer; its synthesis, properties and applications. Russian Chemical Reviews, 66: 443-457.

14. Zhamu, A., Jang, B. Z., and Shi, J. (2010) Graphene nanocomposites for electrochemical cell electrodes. U. S. Patent, 0021819 A1.

15. Armes, S. P. (1987) Optimum reaction conditions for the polymerization of pyrrole by iron (III) chloride in aqueous solution. Synth. Met., 20: 365-371.

16. Zhang, X., Zhang, J., Song, W., and Liu, Z. (2006) Controllable synthesis of conducting polypyrrole nanostructures. J. Phys. Chem. B, 110: 1158-1165.

17. Jeong, H. K., Jin, M. H., So, K. P., Lim, S. C., and Lee, Y. H. (2009) Tailoring the characteristics of graphite oxides by different oxidation times. J. Phys. D Appl. Phys., 42: 65418-65423.

18. Bessel, C. A., Laubernds, K., Rodriguez, N. M., and Baker, R. T. K. (2001) Graphite nanofibers as an electrode for fuel cell applications. J. Phys. Chem. B, 105: $1115-1118$. 
19. Casiraghi, C., Hartschuh, A., Qian, H., Piscanec, S., Georgi, C., Fasoli, A., Novoselov, K. S., Basko, D. M., and Ferrari, A. C. (2009) Raman spectroscopy of graphene edges. Nano Lett., 9: 1433-1441.

20. Liu, Y.C., and Hwang, B. J. (2000) Identification of oxidized polypyrrole on Raman spectrum. Synth. Met., 113: 203-207.

21. Han, G., Yuan, J., Shi, G., and Wei, F. (2005) Electrodeposition of polypyrrole/multiwalled carbon nanotube composite films. Thin Solid Films, 474: 6469.

22. Ferrari, A. C., and Robertson, J. (2000) Interpretation of raman spectra of disordered and amorphous carbon. Phys. Rev. B, 61: 14095-14107.

23. Sato, K., Saito, R., Oyama, Y., Jiang, J., Cançado, L.G., Pimenta, M.A., Jorio, A., Samsonidze, Ge. G., Dresselhaus, G., and Dresselhaus, M. S. (2006) D-band Raman intensity of graphitic materials as a function of laser energy and crystallite size. Chemical Physics Letters, 427: 117-121.

24. Jeong, H. K., Lee, Y. P., Lahaye, R. J. W. E., Park, M. H., An, K. H., Kim, I. J., Yang, C. W., Park, C. Y., Ruoff, R. S., and Lee, Y. H. (2008) Evidence of graphitic AB stacking order of graphite oxides. J. Am. Chem. Soc., 130: 1362-1366.

25. Sahoo, N. G., Jung, Y. C., So, H. H., and Cho, J. W. (2007) Polypyrrole coated carbon nanotubes: Synthesis, characterization, and enhanced electrical properties. Synth. Met. 157: 374-379.

26. Jang, J. Y., Kim, M. S., Jeong, H. M., and Shin, C. M. (2009) Graphite oxide/poly(methyl methacrylate) nanocomposites prepared by a novel method utilizing macroazoinitiator. Composites Science and Technology, 69: 186-191. 
27. Gu, Z., Zhang, L., and Li, C. (2009) Preparation of highly conductive polypyrrole/graphite oxide composites via in situ polymerization. J. Macromol. Sci. Part B Physics, 48. 1093-1102.

28. Stankovich, S., Dikin, D. A., Piner, R. D., Kohlhaas, K. A., Kleinhammes, A., Jia, Y., Wu, Y., Nguyen, S. T., and Ruoff, R. S. (2007) Synthesis of graphene-based nanosheets via chemical reduction of exfoliated graphite oxide. Carbon, 45: 1558-1565. 29. Zengin, H., Zhou, W., Jin, J., Czerw, R., Smith Jr., D. W., Echegoyen, L., Carroll, D. L., Foulger, S. H., and Ballato, J. (2002) Carbon nanotube doped polyaniline. Adv. Mater., 14: 1480-1483. 


\section{Figure Captions}

Figure 1. SEM images of (a) and (b) pristine PPy at different magnifications.

Figure 2. SEM images of (a) GO sheets and (b) PPy coated GO sheets (the ratio by weight between Py and GO sheets as 1:1).

Figure 3. SEM images of (a) graphene nanosheets obtained after chemical reduction of GO sheets and (b) PPy/graphene nanosheet composites (the ratio by weight between Py and graphene nanosheets as 1:1).

Figure 4. XRD patterns of (a) pristine PPy, (b) GO sheets, (c) Py:GO sheets=1:1 and (d) Py:GO sheets=2:1.

Figure 5. Percent crystallinity changes of GO sheets and PPy/GO based nanocomposites.

Figure 6. Raman spectrum of pristine PPy.

Figure 7. Raman spectrum of GO sheets after 10 days of oxidation.

Figure 8. Raman spectra of (a) Py:GO sheets=1:1 and (b) Py:GO sheets=2:1.

Figure 9. Raman spectra of (a) reduced GO sheets (graphene nanosheets) and (b) Py:graphene nanosheets $=1: 1$.

Figure 10. $\mathrm{I}_{\mathrm{D}} / \mathrm{I}_{\mathrm{G}}$ ratio changes of graphite, GO sheets, and reduced GO sheets.

Figure 11. TGA curves of GO sheets, Py:GO sheets=1:1, Py:GO sheets=2:1, and pristine PPy in air atmosphere.

Figure 12. TGA curves of graphene nanosheets, Py:graphene nanosheets=1:1nanocomposite, and pristine PPy in air atmosphere.

Figure 13. 3D AFM images by tapping mode of (a) pristine PPy, (b) Py:GO sheets=1:1 and (c) Py:GO sheets=2:1. 


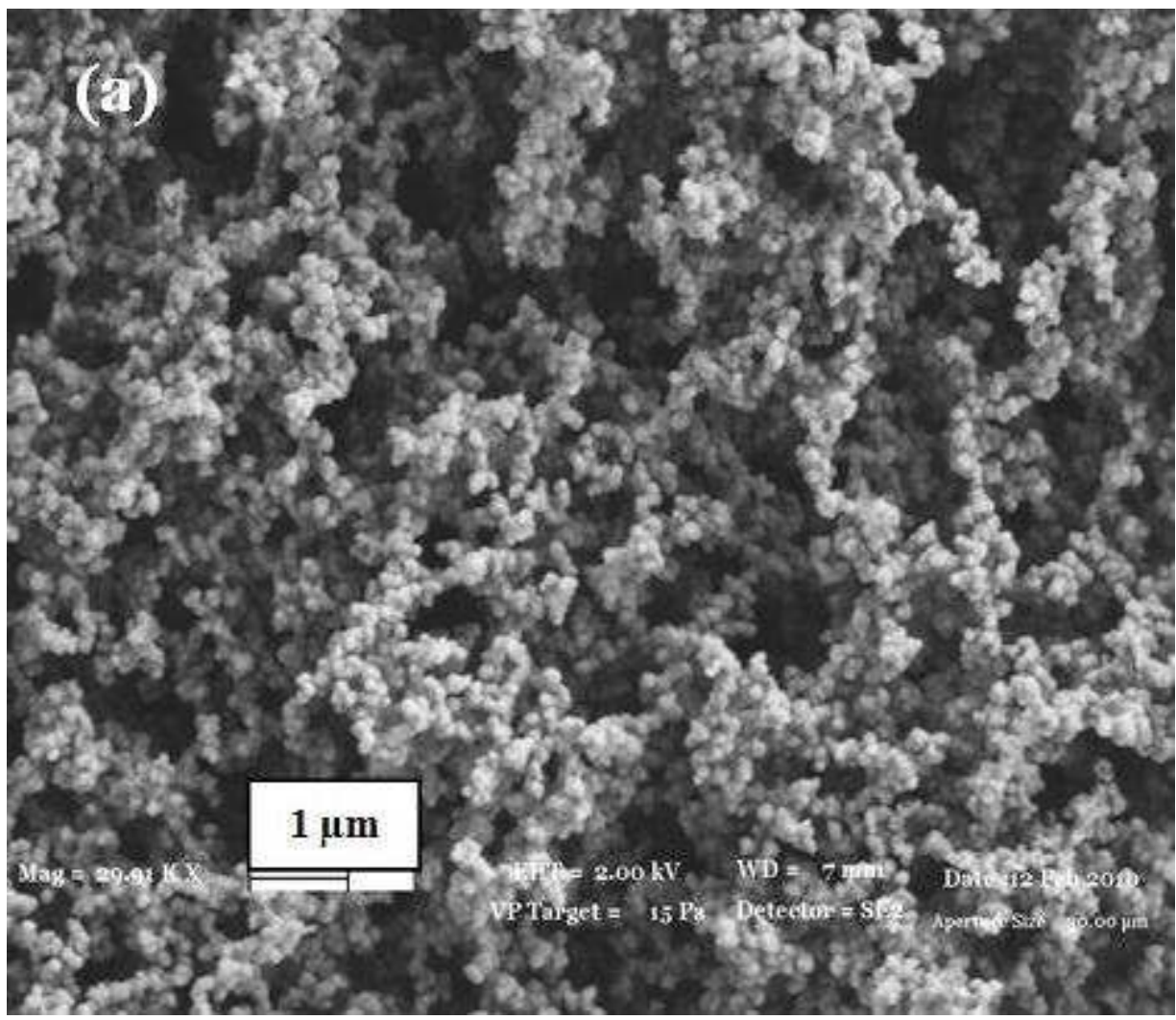

SEM images of pristine PPy at different magnifications $123 \times 106 \mathrm{~mm}(96 \times 96 \mathrm{DPI})$ 


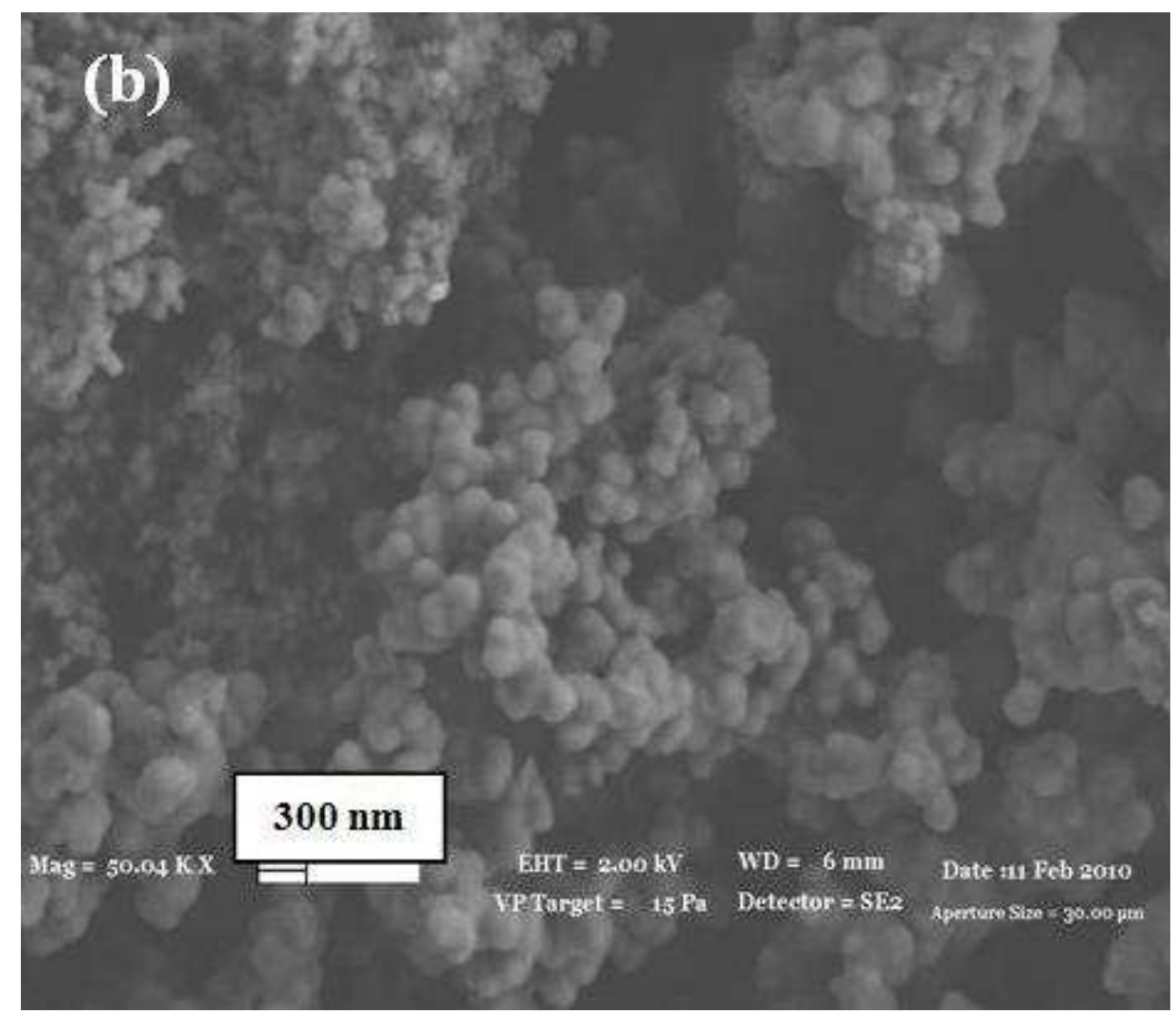

SEM images of pristine PPy at different magnifications $123 \times 106 \mathrm{~mm}(96 \times 96 \mathrm{DPI})$ 


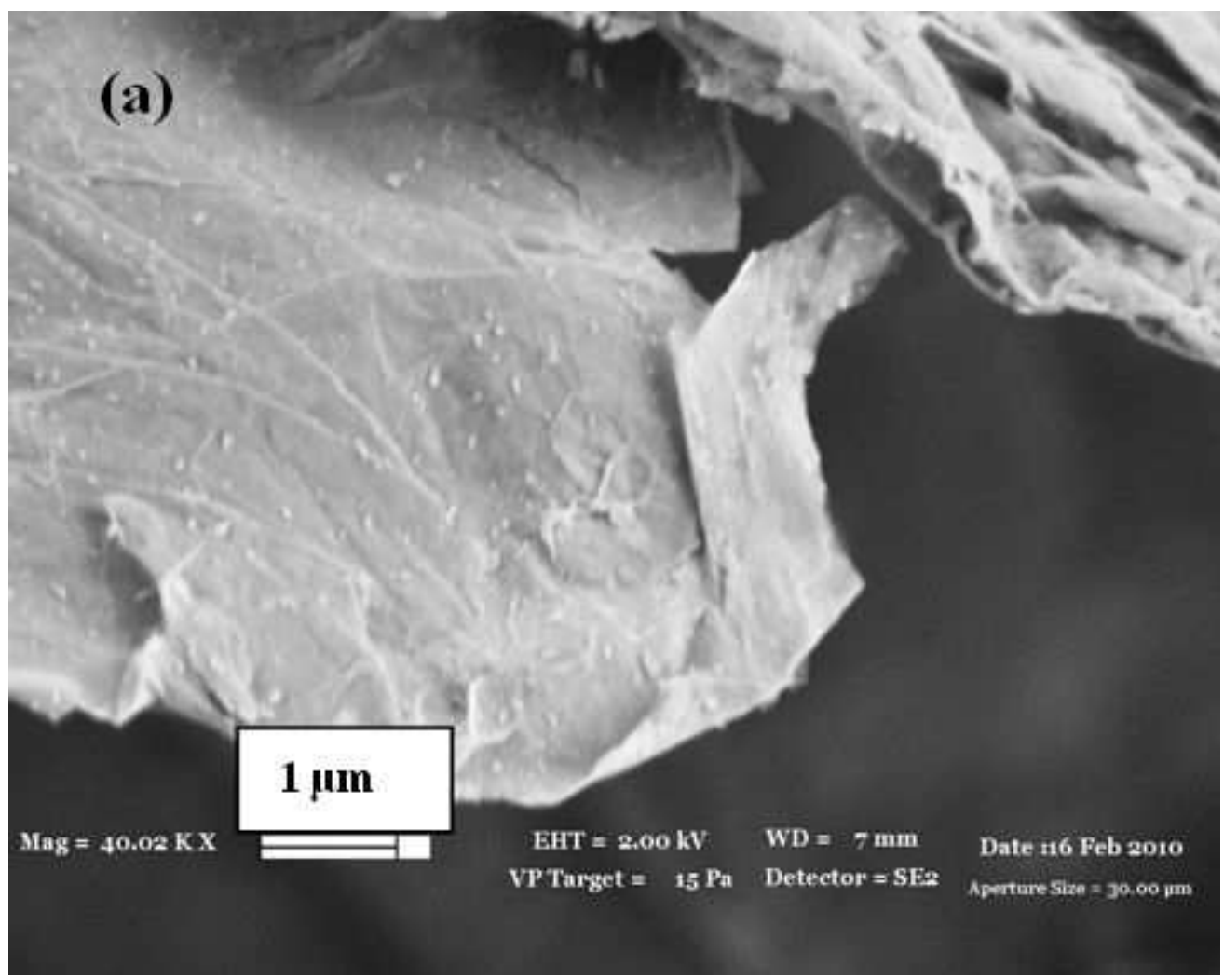

SEM images of GO sheets 


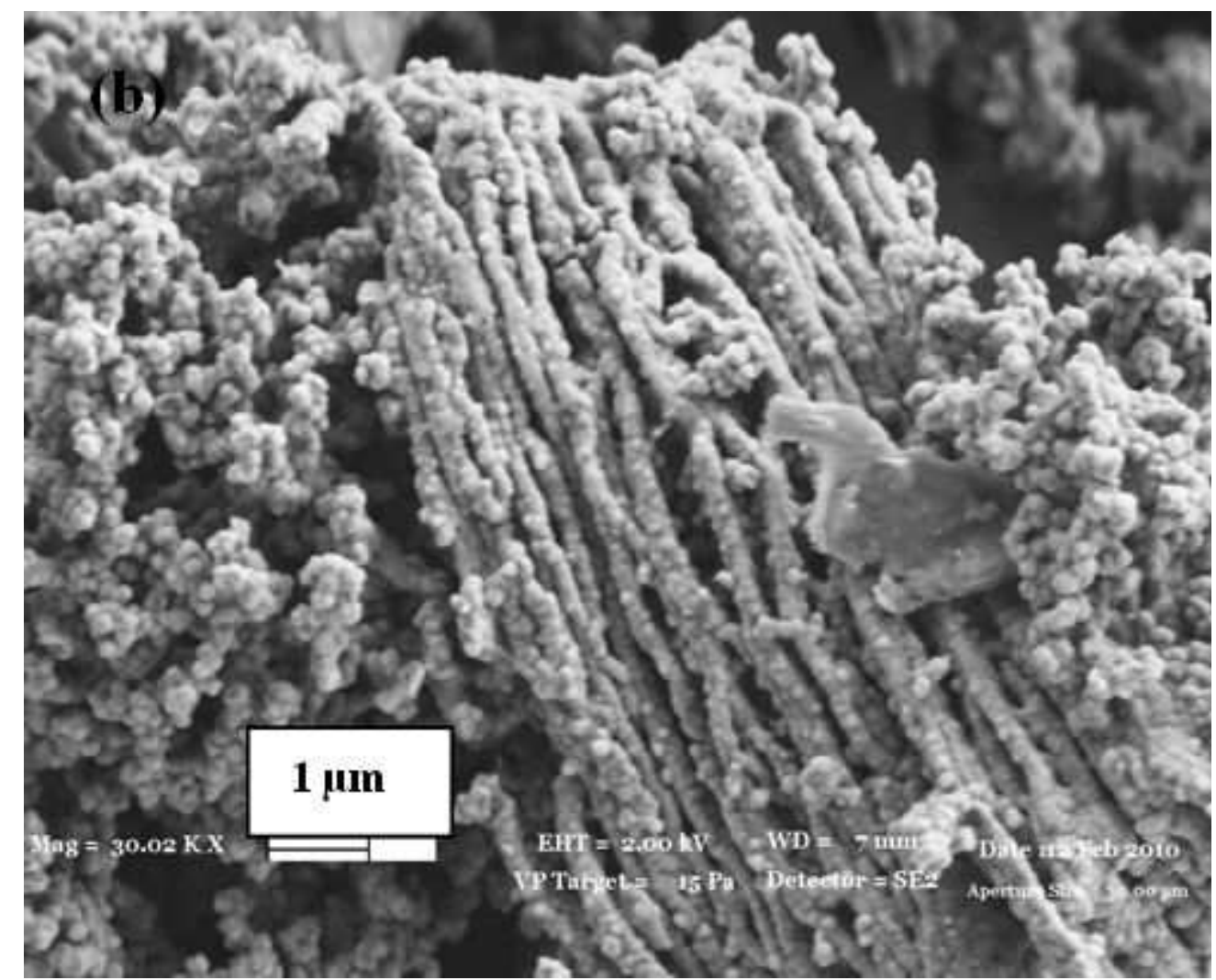

SEM image of PPy coated GO sheets (the ratio by weight between Py and GO sheets as $1: 1$ )

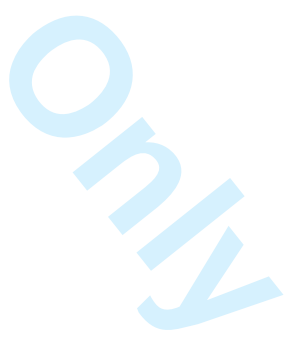




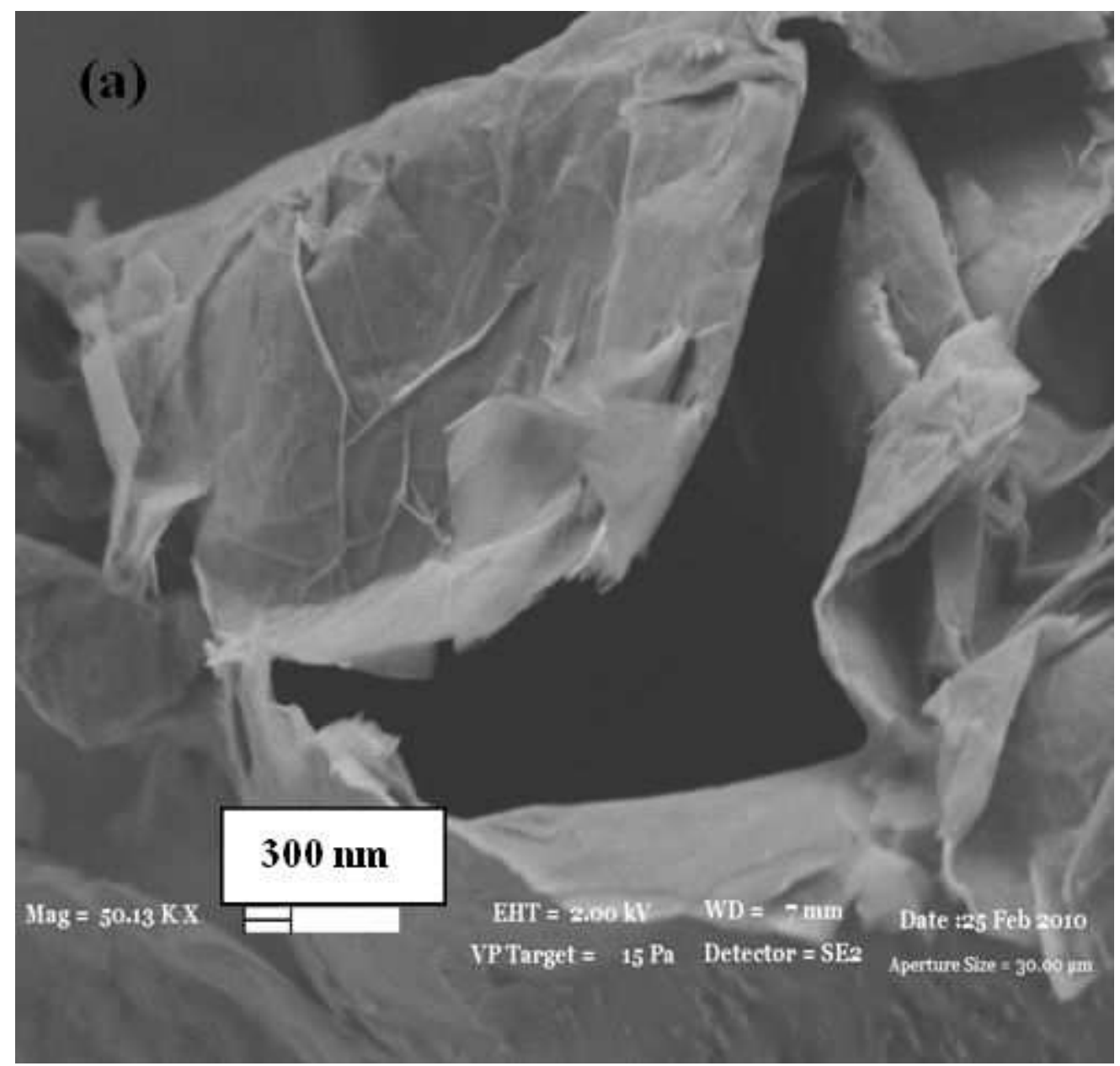

SEM images of graphene nanosheets obtained after chemical reduction of GO sheets 


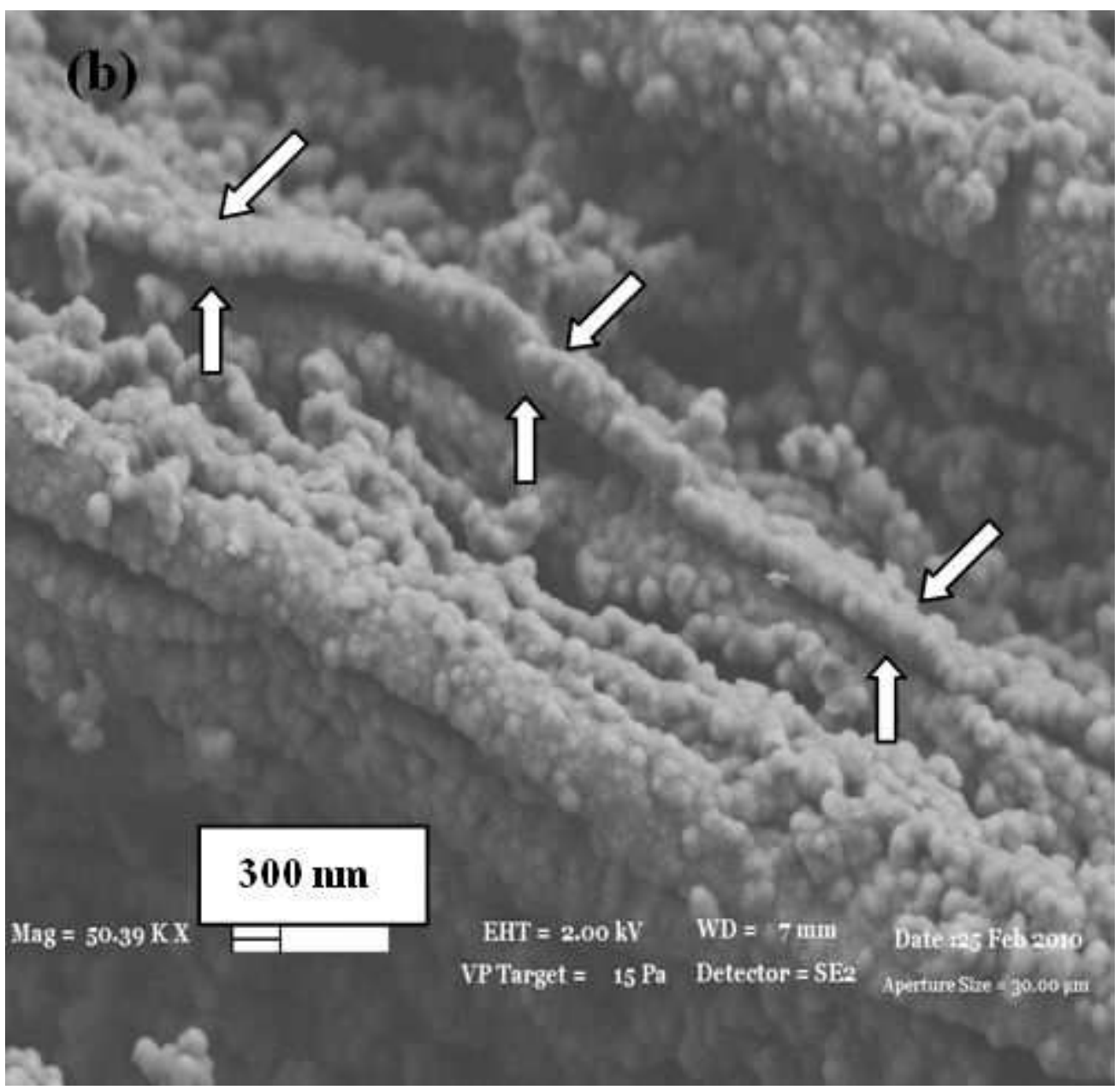

SEM images of PPy/graphene nanosheet composites (the ratio by weight between Py and graphene nanosheets as $1: 1$ ) 


1
2
3
4
5
6
7
8
9
10
11
12
13
14
15
16
17
18
19
20
21
22
23
24
25
26
27
28
29
30
31
32
33
34
35
36
37
38
39
40
41
42
43
40
45
49
50
51
52
53
55
50

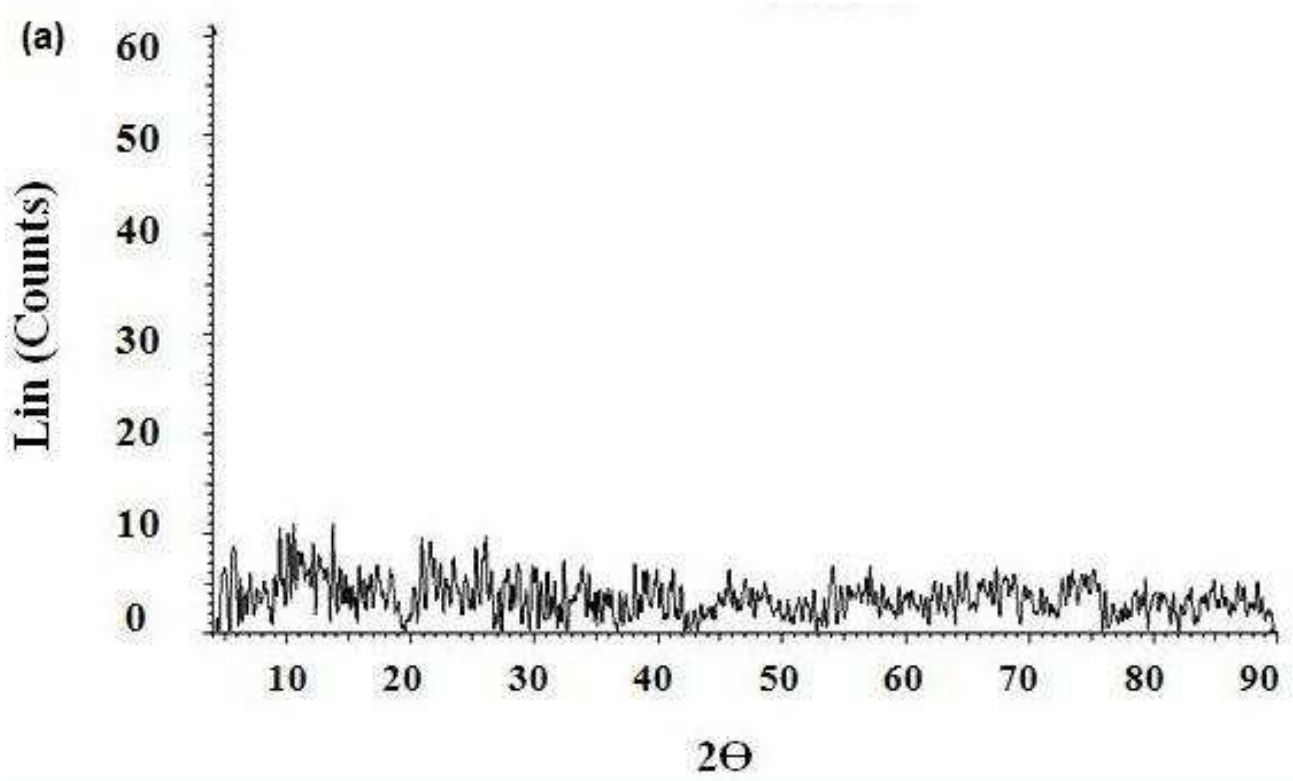

XRD patterns of pristine PPy $150 \times 90 \mathrm{~mm}(96 \times 96 \mathrm{DPI})$ 


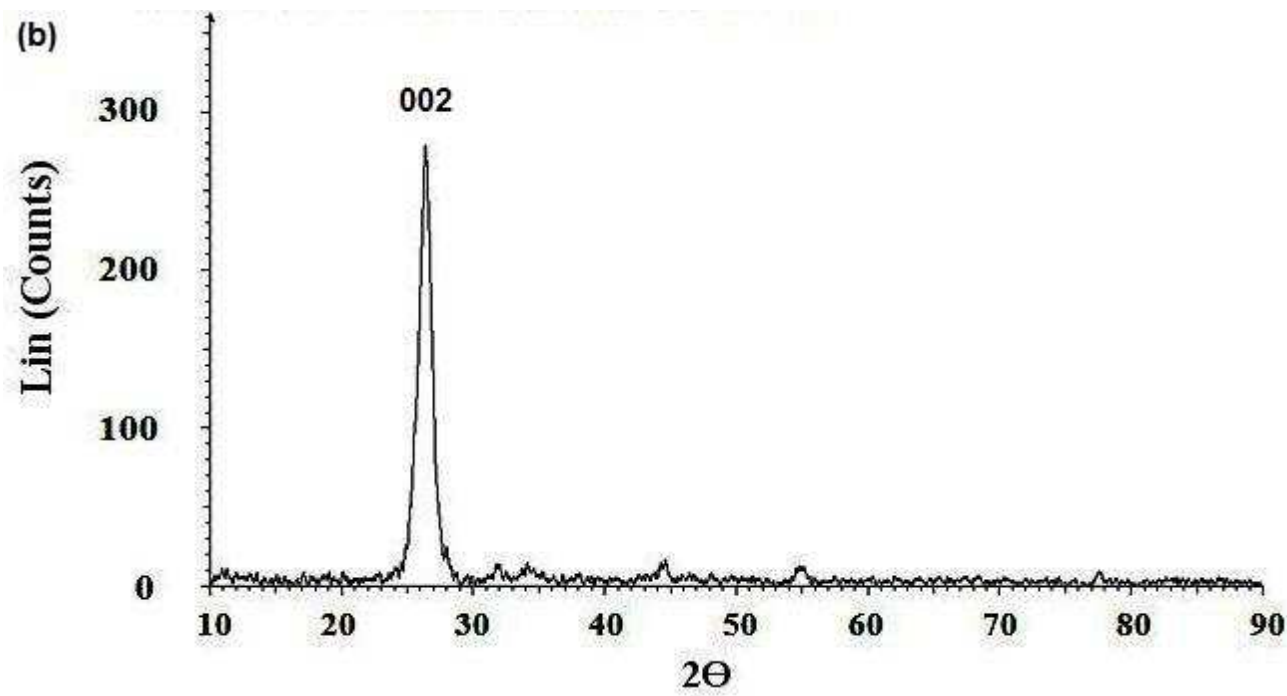

XRD patterns of GO sheets $172 \times 92 \mathrm{~mm}(96 \times 96 \mathrm{DPI})$ 


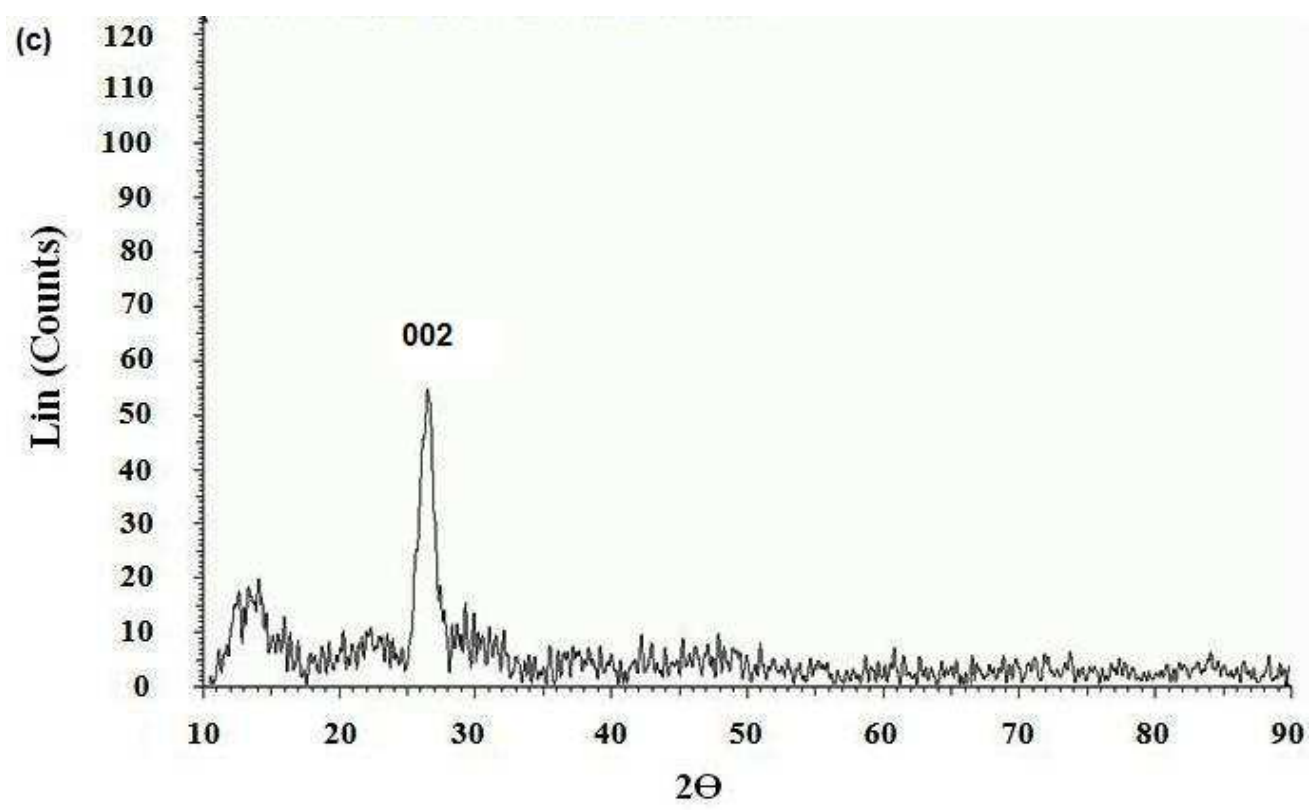

XRD patterns of Py: $\mathrm{GO}$ sheets $=1: 1$ $181 \times 110 \mathrm{~mm}(96 \times 96$ DPI $)$ 


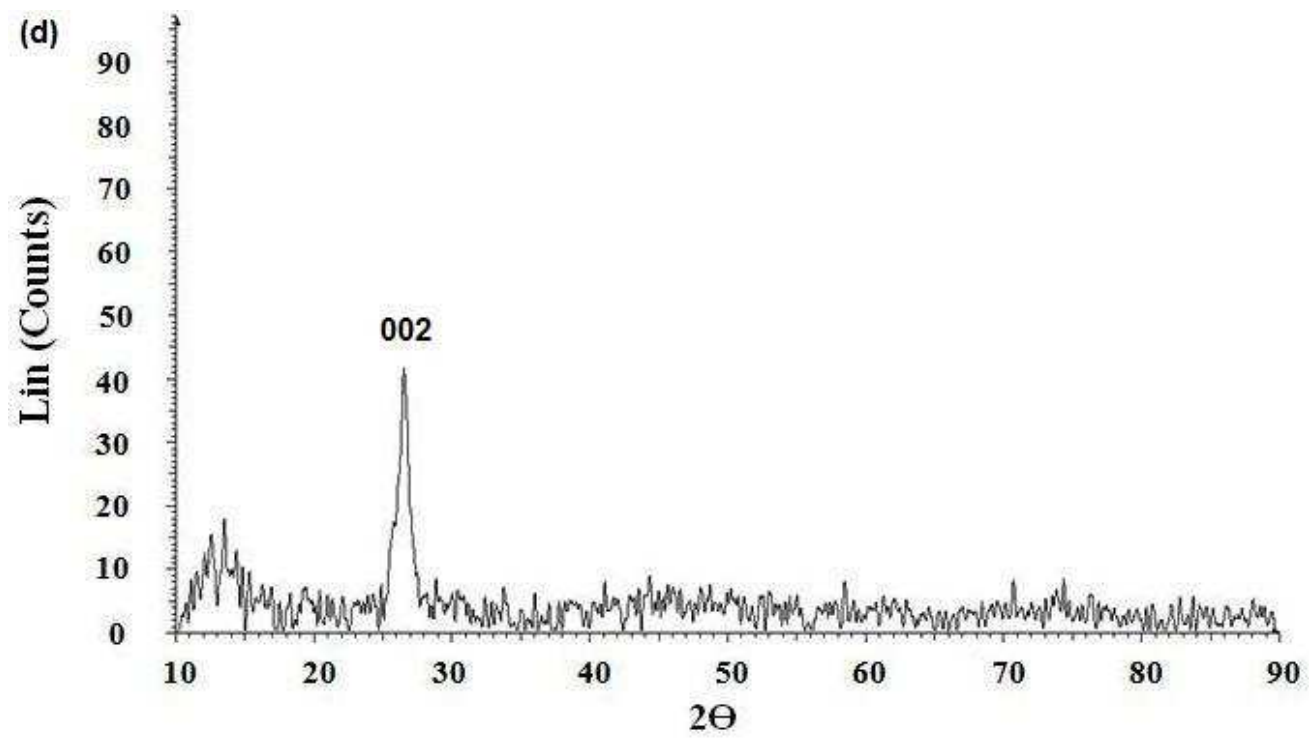

XRD patterns of Py:GO sheets $=2: 1$. $178 \times 100 \mathrm{~mm}(96 \times 96 \mathrm{DPI})$ 


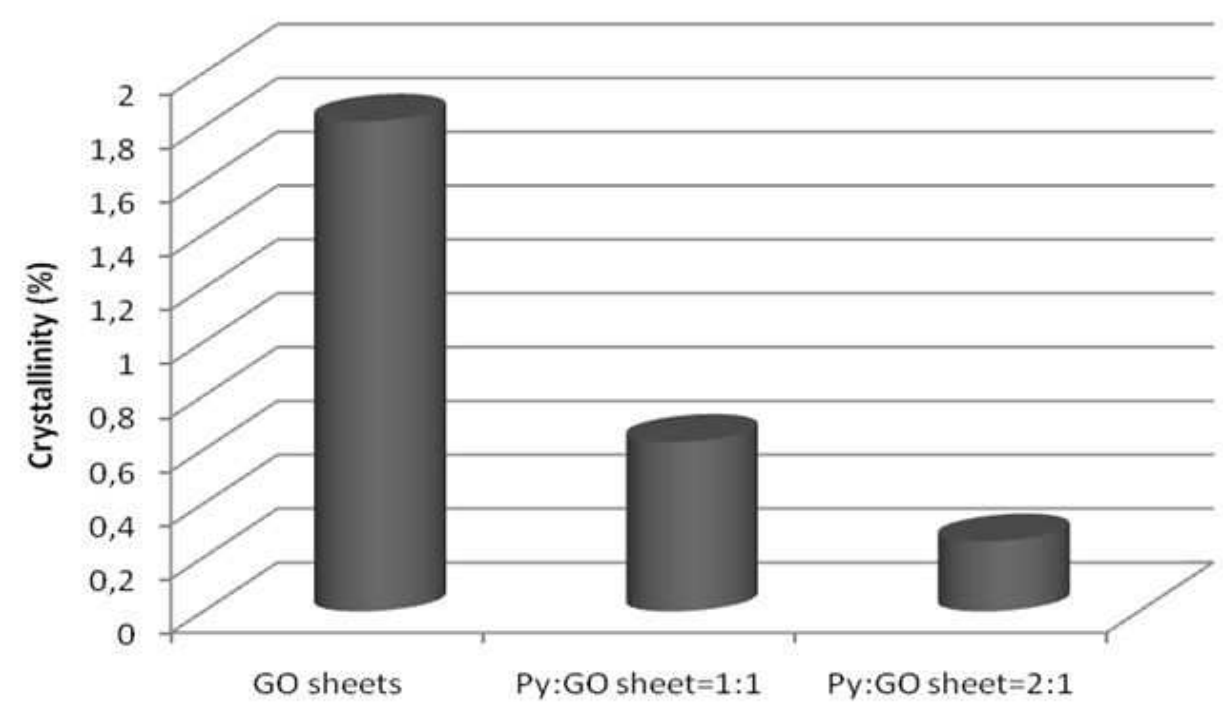

Percent crystallinity changes of GO sheets and PPy/GO based nanocomposites 


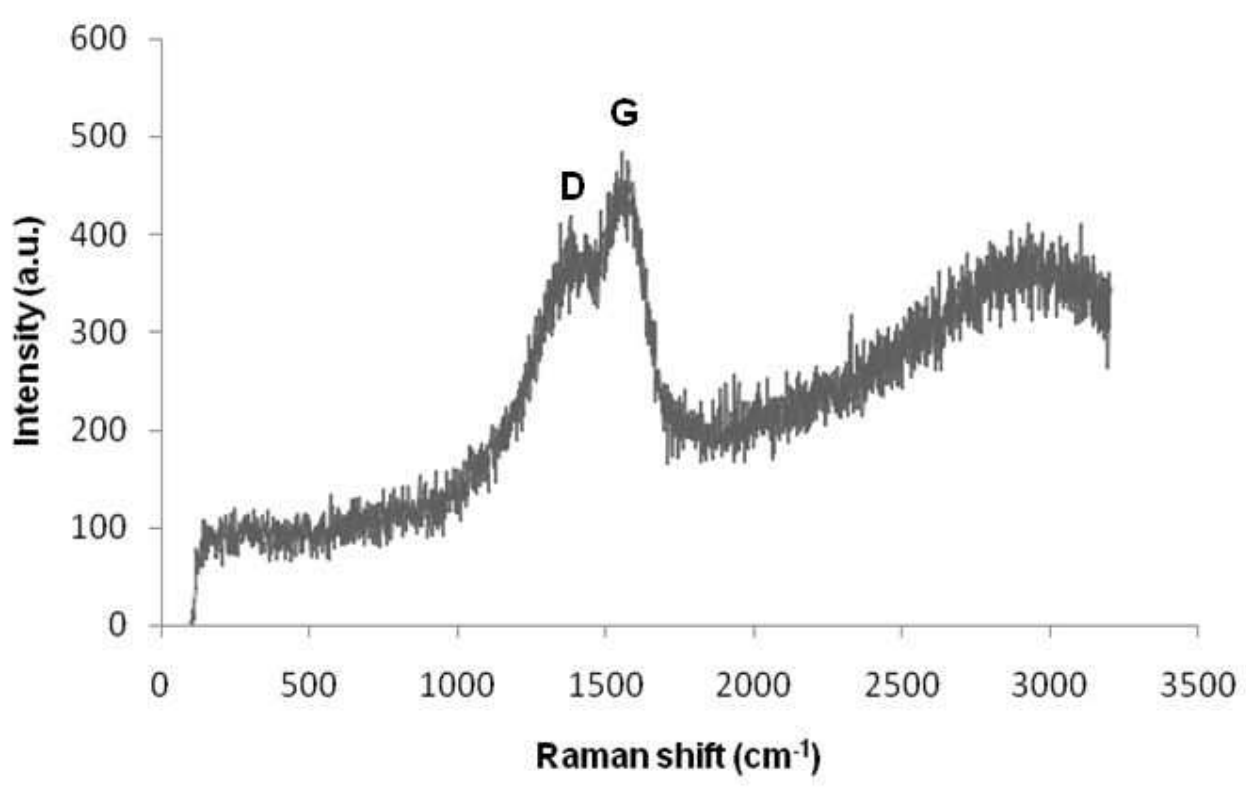

Raman spectrum of pristine PPy. 


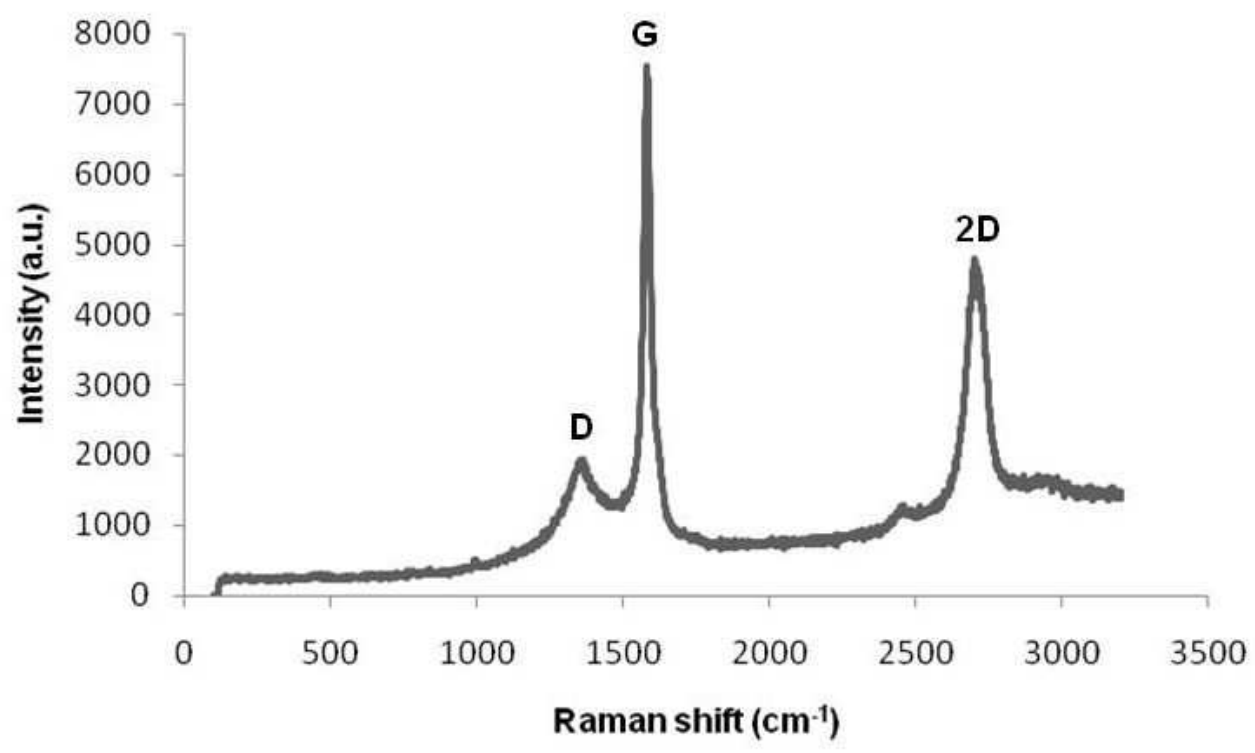

Raman spectrum of $\mathrm{GO}$ sheets after 10 days of oxidation $198 \times 118 \mathrm{~mm}(96 \times 96$ DPI $)$ 


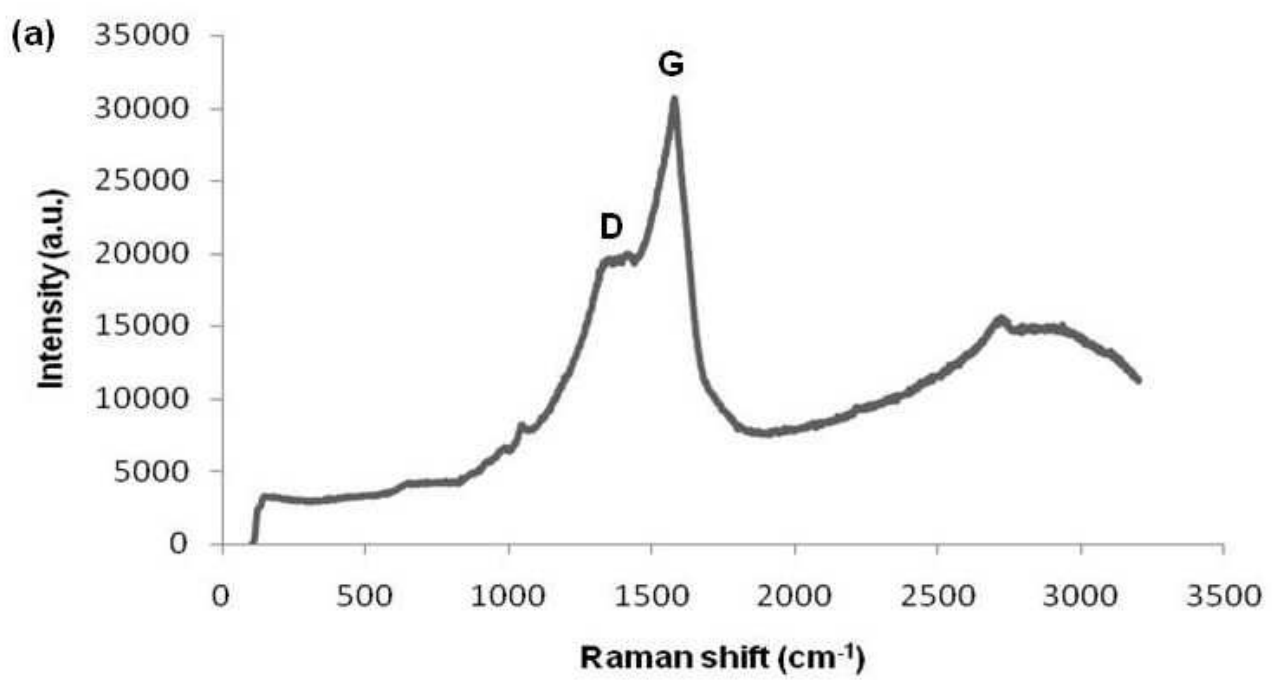

Raman spectra of Py:GO sheets $=1: 1$ $198 \times 108 \mathrm{~mm}(96 \times 96 \mathrm{DPI})$ 


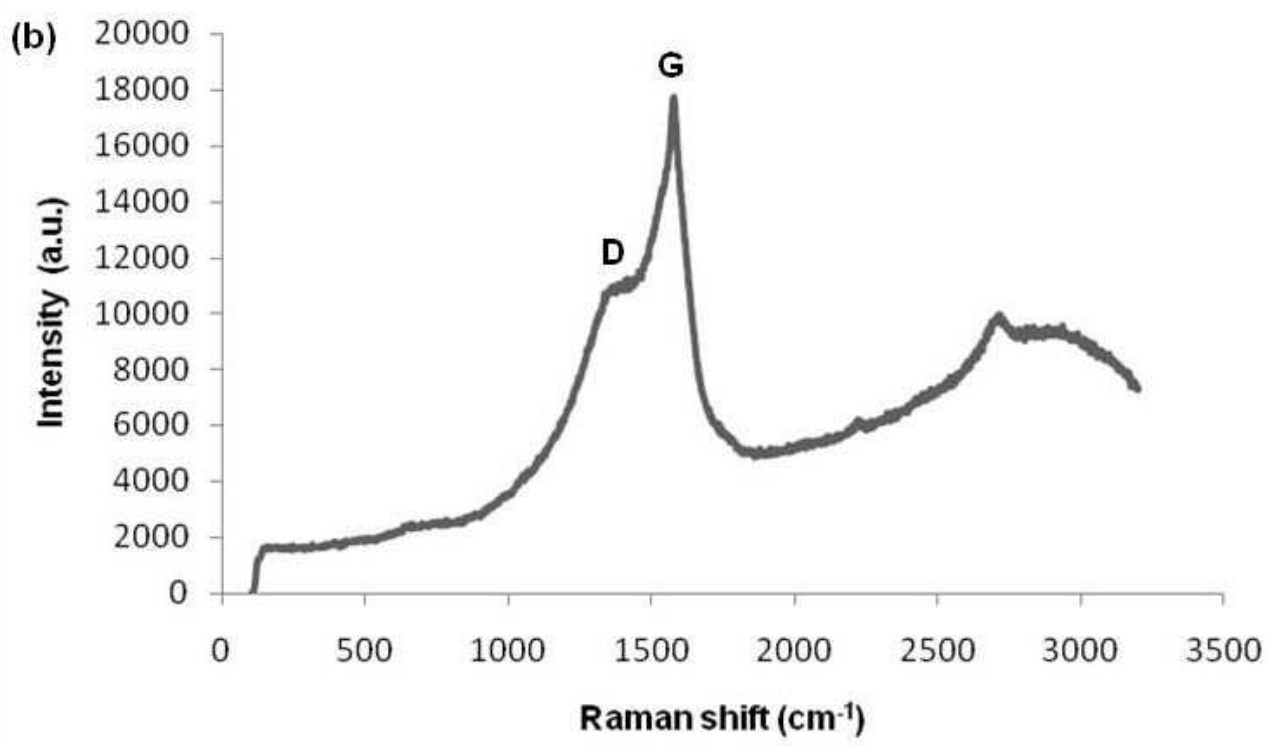

Raman spectra of Py: GO sheets $=2: 1$ $198 \times 118 \mathrm{~mm}(96 \times 96 \mathrm{DPI})$ 


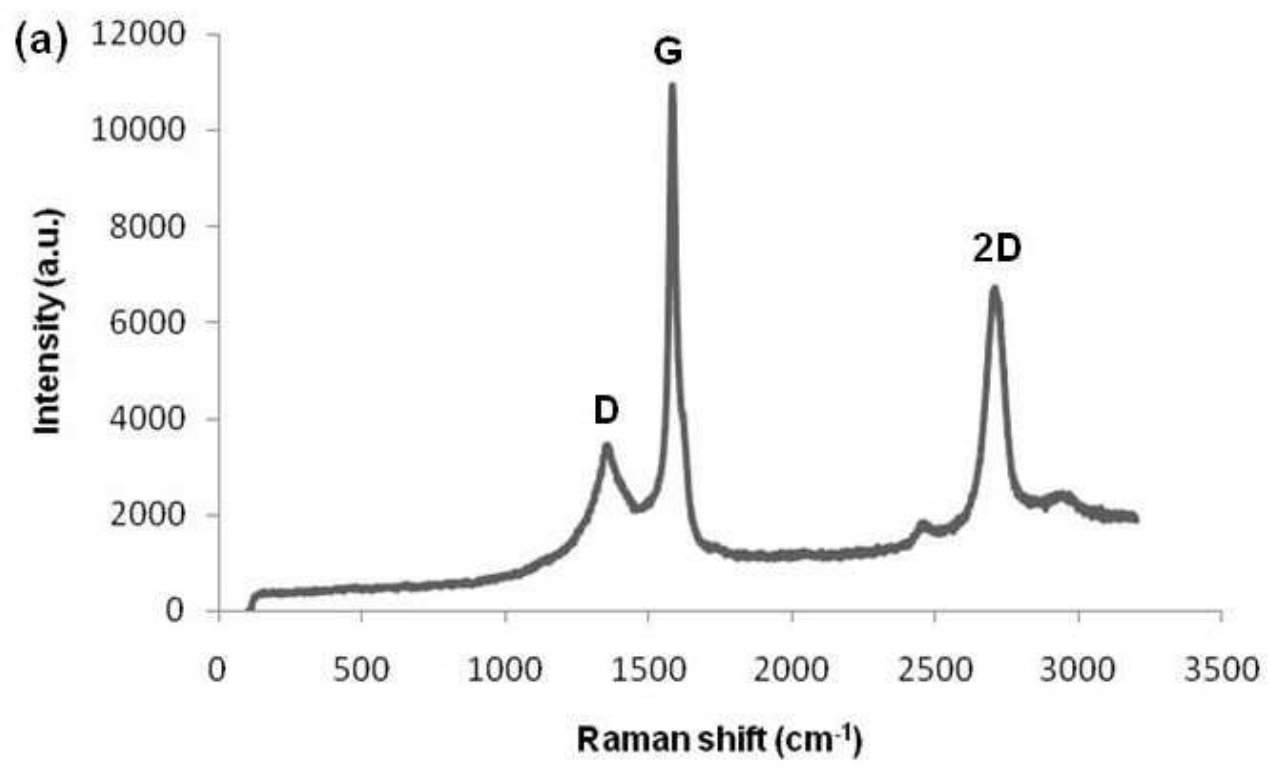

Raman spectra of reduced GO sheets (graphene nanosheets) $180 \times 110 \mathrm{~mm}(96 \times 96 \mathrm{DPI})$ 


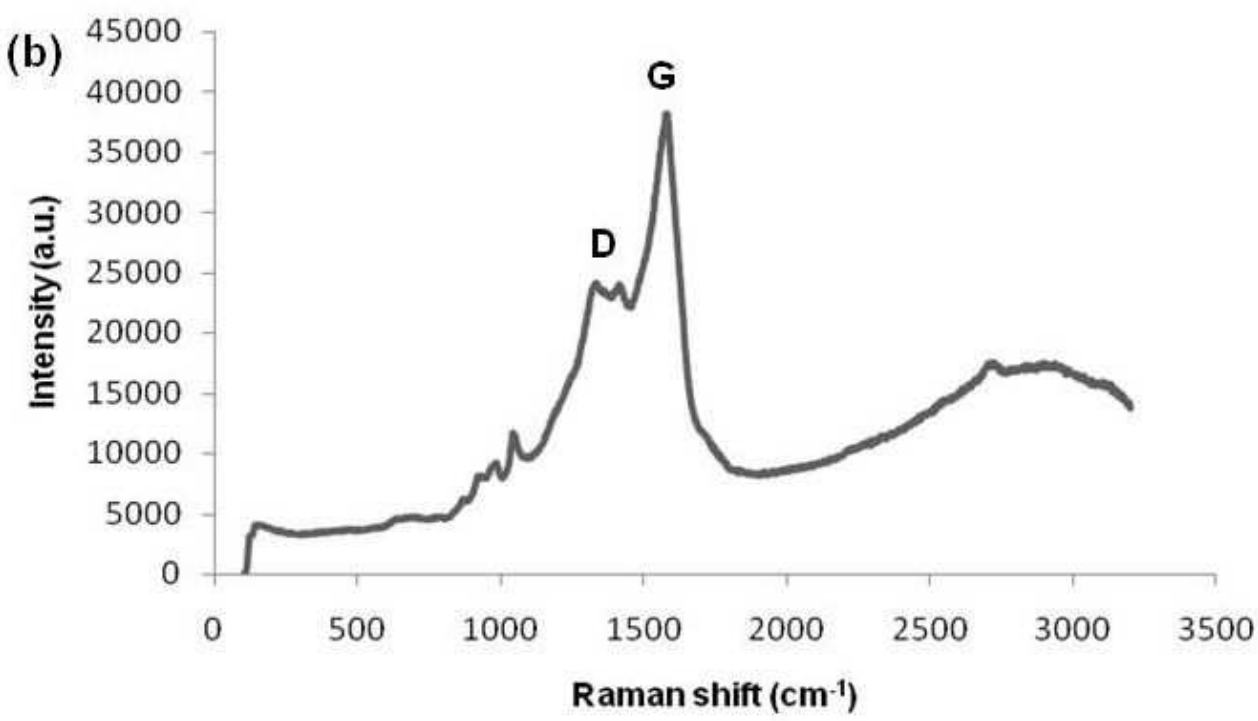

\section{Raman spectra of Py:graphene nanosheets $=1: 1$.} $180 \times 103 \mathrm{~mm}(96 \times 96 \mathrm{DPI})$ 


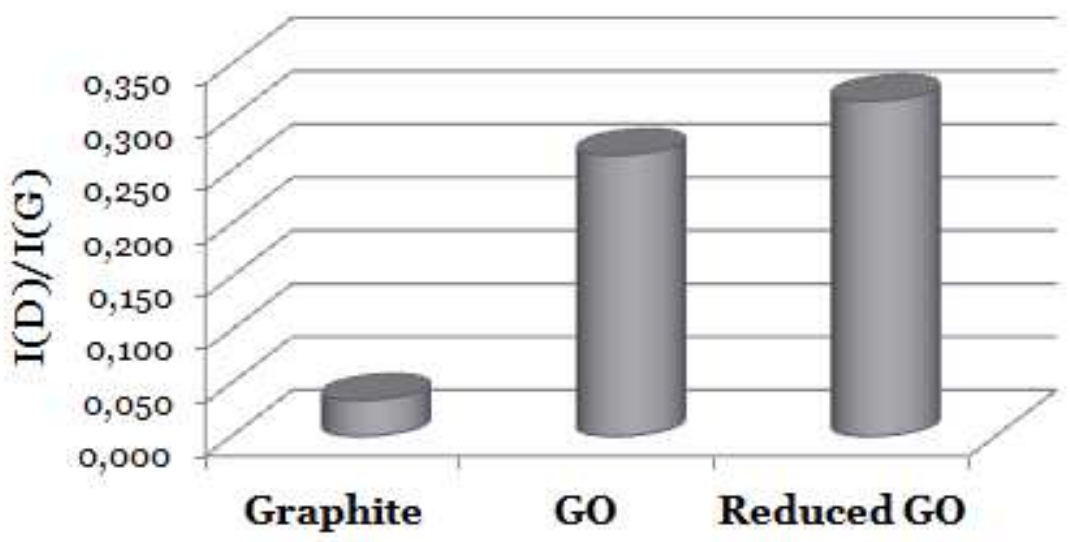

ID/IG ratio changes of graphite, GO sheets, and reduced GO sheets 


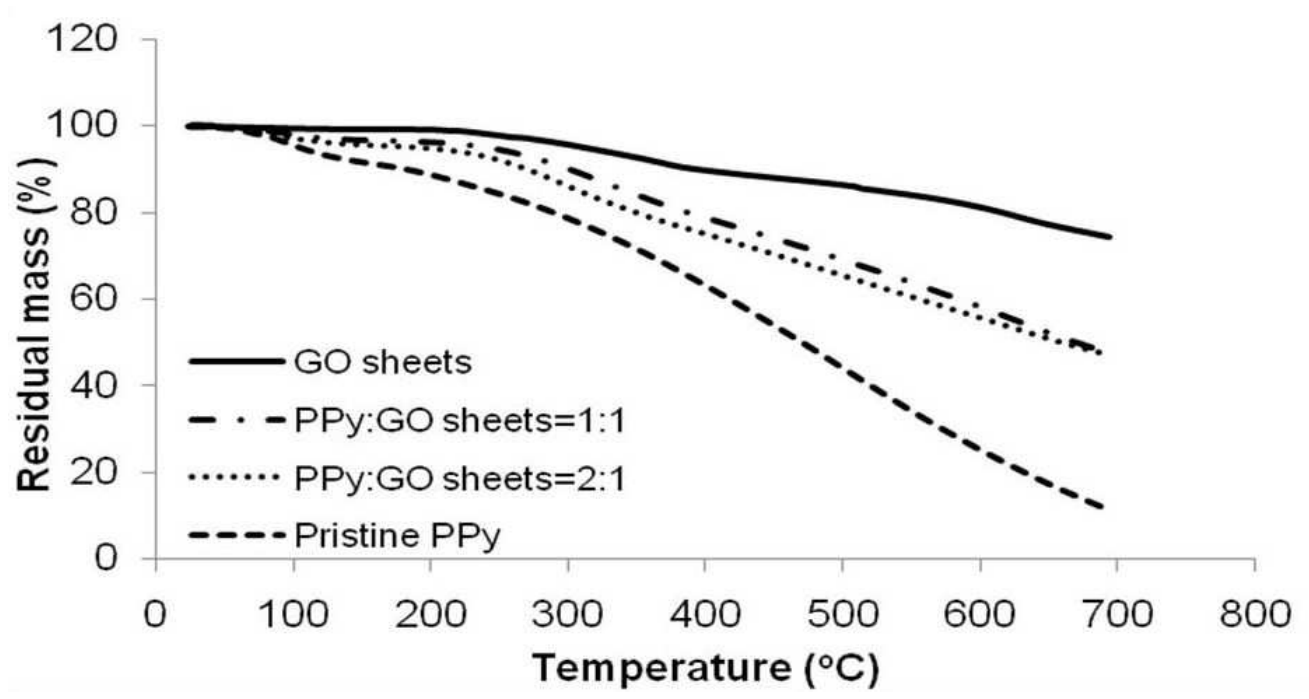

TGA curves of GO sheets, Py:GO sheets $=1: 1$, Py:GO sheets $=2: 1$, and pristine PPy in air atmosphere.

$246 \times 129 \mathrm{~mm}(96 \times 96 \mathrm{DPI})$ 


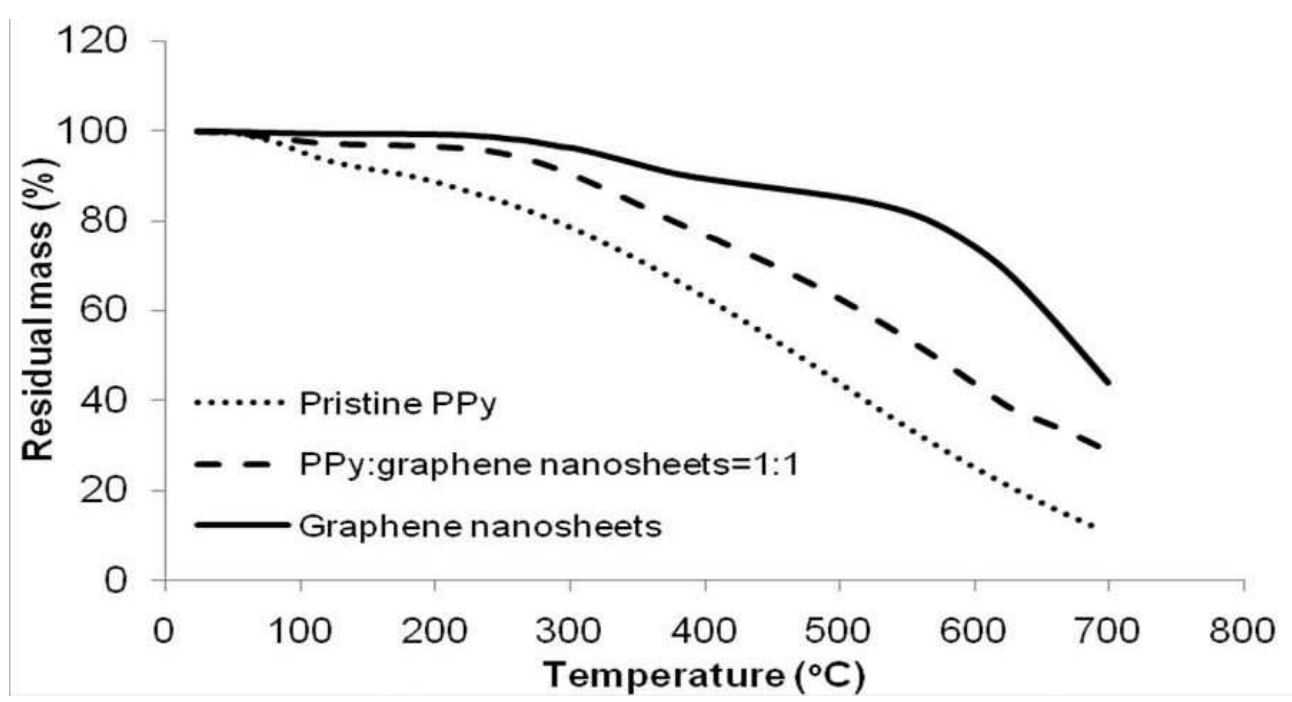

TGA curves of graphene nanosheets, Py:graphene nanosheets=1:1-nanocomposite, and pristine PPy in air atmosphere. 240x125mm (96 x 96 DPI) 

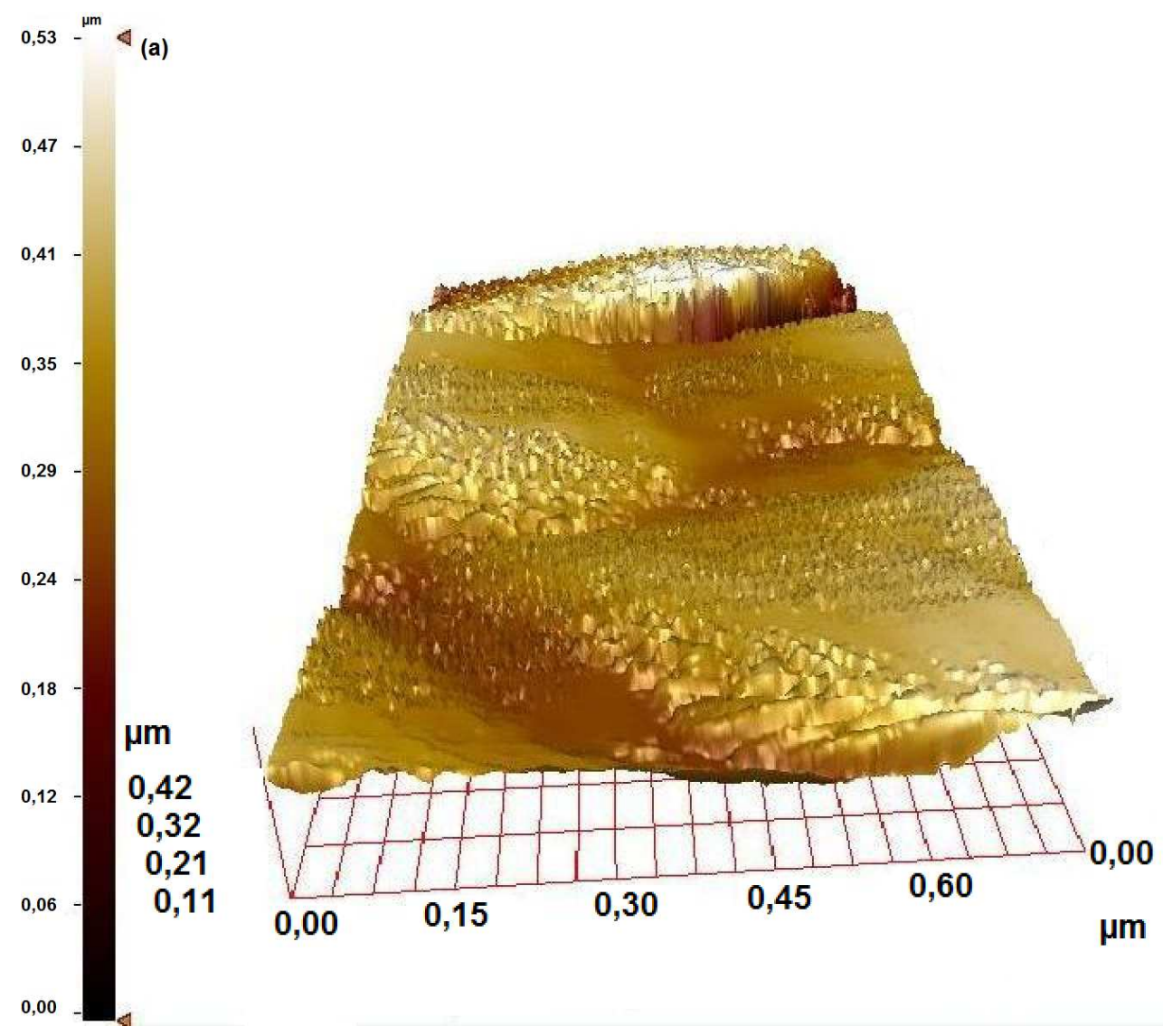

3D AFM images by tapping mode of pristine PPy $361 \times 312 \mathrm{~mm}(96 \times 96 \mathrm{DPI})$ 


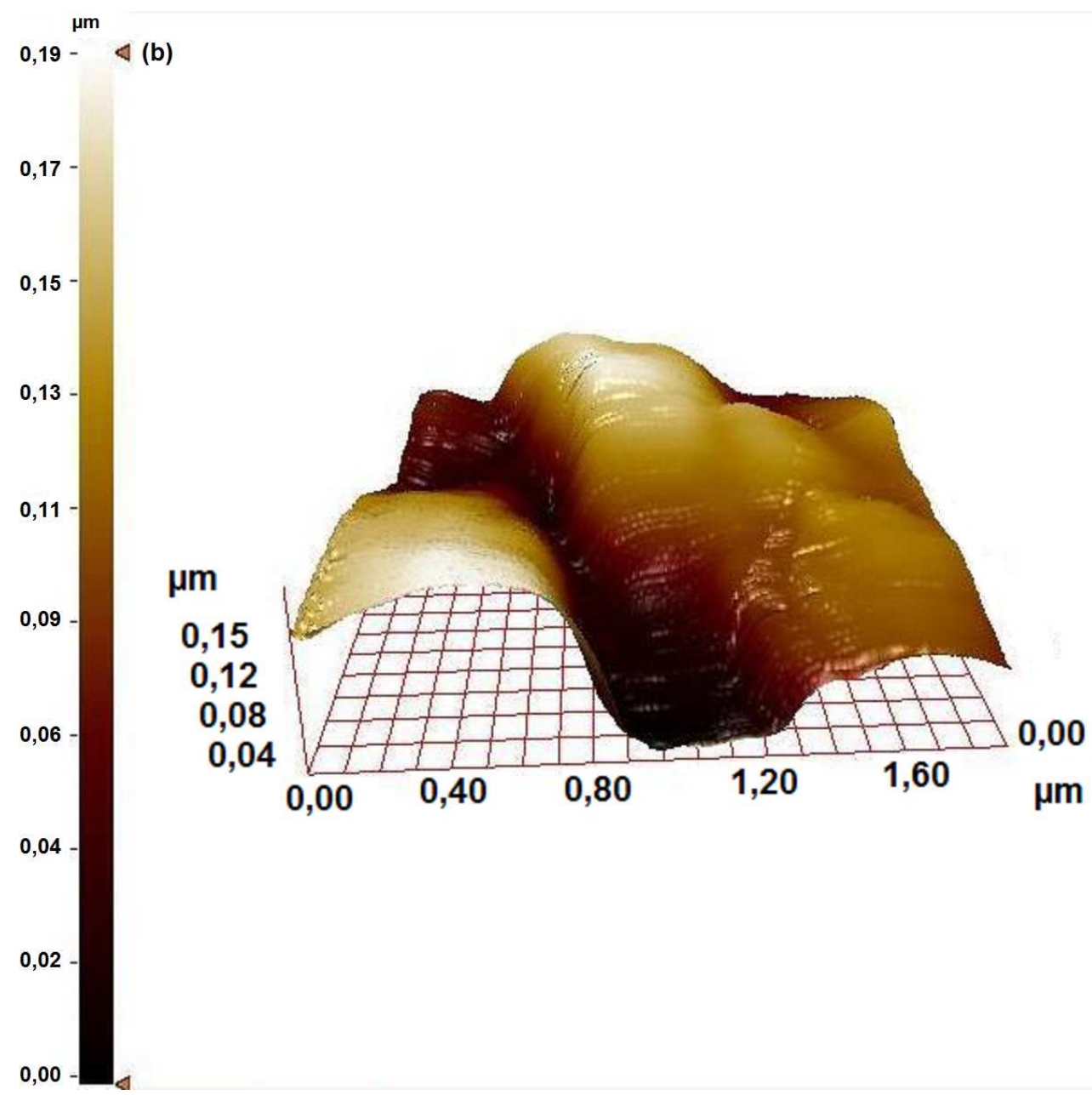

3D AFM images by tapping mode of Py:GO sheets $=1: 1$ $324 \times 316 \mathrm{~mm}(96 \times 96 \mathrm{DPI})$ 


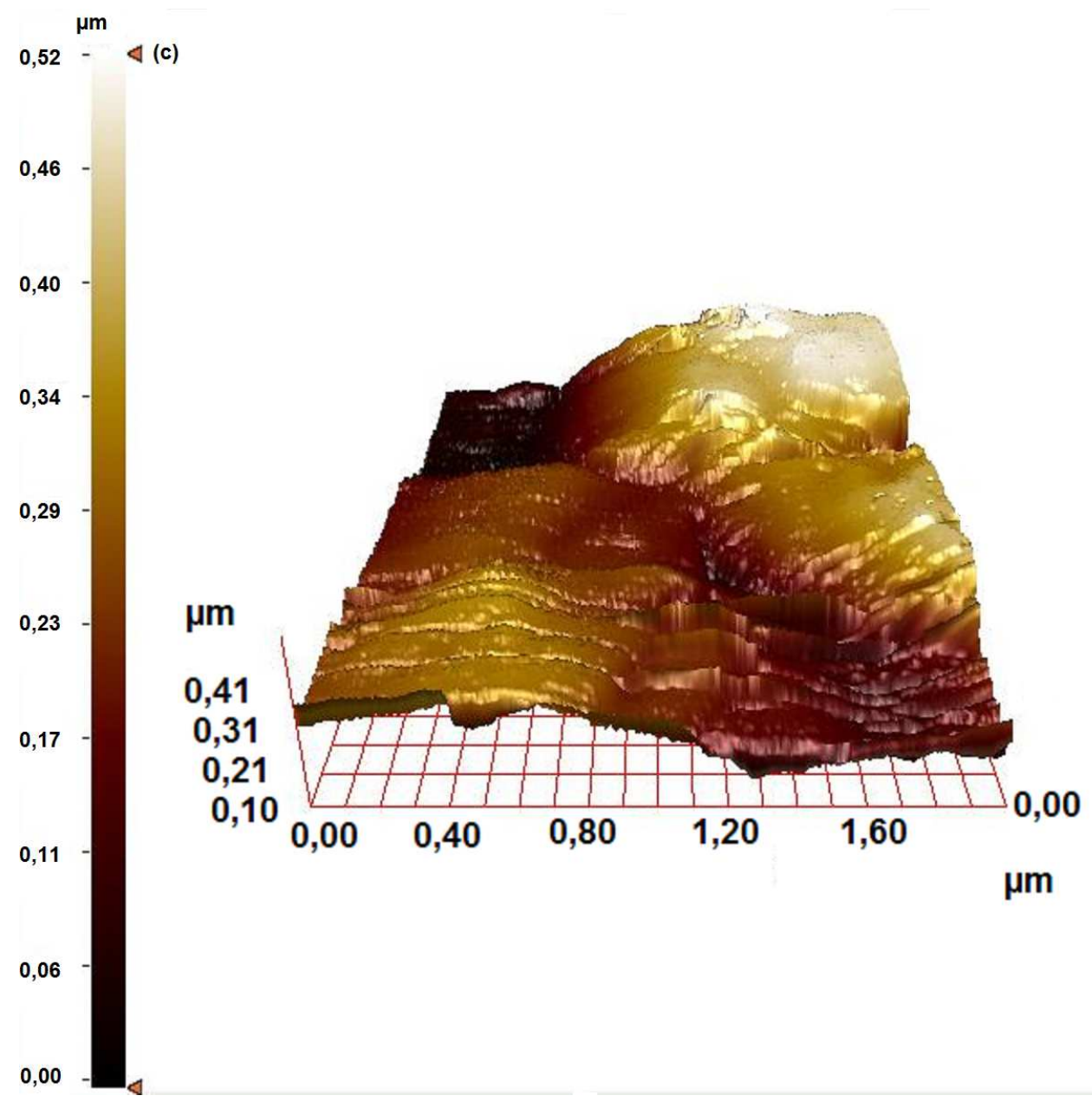

3D AFM images by tapping mode of Py:GO sheets $=2: 1$ $330 \times 318 \mathrm{~mm}(96 \times 96 \mathrm{DPI})$ 


\section{Table Captions}

Table 1

Electrical conductivity results of pristine PPy, GO sheets and PPy/GO nanocomposites

Table 2

Electrical conductivity results of pristine PPy, reduced GO sheets, PPy/Graphene nanosheet composite 
Electrical conductivity results of pristine $\mathrm{PPy}, \mathrm{GO}$ sheets and $\mathrm{PPy} / \mathrm{GO}$ nanocomposites

\begin{tabular}{ll}
\hline Samples & Conductivity $(\mathbf{S} / \mathbf{c m})$ \\
\hline Pristine PPy & $7.6 \times 10^{-4}$ \\
GO sheets & 0.69 \\
Nanocomposite-1 (Py:GO sheets=1:1) & 0.08 \\
Nanocomposite-2 (Py:GO sheets=2:1) & 0.05 \\
\hline
\end{tabular}

\section{Table 1}


Table 2

Electrical conductivity results of pristine PPy, reduced GO sheets, PPy/Graphene nanosheet composite

\begin{tabular}{ll}
\hline Samples & Conductivity $(\mathbf{S} / \mathbf{c m})$ \\
\hline Pristine PPy & $7.6 \times 10^{-4}$ \\
Reduced GO sheets (graphene nanosheets) & 3.96 \\
Nanocomposite (Py:Reduced GO=1:1) & 0.13 \\
\hline
\end{tabular}

